\title{
Utilização da regressão quantílica local na construção de curvas de referência
}

\author{
Gianni Yanaguibashi \\ Dissertação apresentada ao \\ Instituto de Matemática e Estatística \\ da Universidade de São Paulo \\ para obtenção do grau de \\ Mestre em Estatística. \\ Área de Concentração: Estatística \\ Orientadora: Prof. ${ }^{\mathbf{a}}$ Dr. ${ }^{\mathbf{a}}$ Carmen Diva Saldiva de André
}

São Paulo, Novembro de 2005. 


\title{
Utilização da regressão quantílica local na construção de curvas de referência
}

\author{
Este exemplar corresponde à redação final \\ da dissertação devidamente corrigida e \\ defendida por Gianni Yanaguibashi \\ e aprovada pela comissão julgadora.
}

São Paulo, 21 de novembro de 2005.

Banca Examinadora:

- Prof. ${ }^{\text {a }}$ Dr. ${ }^{\text {a }}$ Carmen Diva Saldiva de André (presidente) - Instituto de Matemática e Estatística/USP

- Prof. Dr. Clóvis de Araújo Peres - Instituto de Matemática e Estatística/USP

- Prof. Dr. Ronaldo Dias - Instituto de Matemática, Estatística e Computação Científica/UNICAMP 
"De tudo ficaram três coisas:

A certeza de que estamos começando,

a certeza de que é preciso continuar

e a certeza de que podemos ser interrompidos

antes de terminar.

Façamos da interrupção um caminho novo.

Da queda um passo de dança, do medo uma escada.

do sonho uma ponte,

da procura um encontro!"

(Fernando Sabino) 
As minhas filhas,

ao meu marido $e$

a minha mãe. 


\section{Agradecimentos}

Agradeço a todos que contribuíram para a elaboração deste trabalho, em especial:

À querida professora Carmen pela dedicada orientação, confiança, apoio e amizade.

As minhas adoráveis filhas Laura e Luciana pelo carinho, compreensão e apoio durante esta jornada.

Ao meu marido Fernado que esteve comigo em todos os momentos.

A minha mãe Zoneide e ao meu pai Ezequias pela atenção e estímulo, mesmo estando distante.

Aos meus irmãos Mara, Giovanni e Juliano pela energia positiva que sempre recebi.

A fiel companheira de casa Valentina por ser uma excelente administradora do meu lar.

Aos meus queridos amigos Regina e Fábio pelos preciosos momentos compartilhados no IME/USP e na UNIFESP.

Aos amigos Tatiana e Marcos Vincenzi pela imensa ajuda no ATEX.

Aos companheiros de trabalho Pedro e Cátia por compartilharem os mesmos direitos e deveres do mestrado.

Ao professor Ronaldo Dias pelos conhecimentos iniciais do Software R e pelas valiosas sugestões apresentadas por ocasião da defesa.

Aos professores Clóvis de Araújo Peres, Júlio da Motta Singer, Marcos Nascimento Magalhães, Mônica Carneiro Sandoval e Chang Chiann que estavam comigo 
ao longo do mestrado.

A todos aqueles que contribuíram para este trabalho. Entre eles, Daniel, Marcel, Marcelo, Elaine e Cecília.

Por fim, agradeço a Deus por ter permitido que tantos amigos fizessem parte desta grande conquista. 


\section{Resumo}

As curvas de referência são bastante utilizadas em problemas reais em que se deseja avaliar se as unidades amostrais seguem, ou não, um padrão de "normalidade", segundo alguma característica de interesse. Na área médica, por exemplo, as curvas de referência, por refletirem o comportamento dos indivíduos saudáveis, fornecem uma espécie de guia clínico para interpretar a informação de um novo paciente. A construção das curvas de referência envolve a estimação dos quantis populacionais da distribuição da variável resposta $Y$, em diferentes valores da variável preditora $X$. Com o objetivo de construir curvas de referência, nos restringimos neste trabalho, à apresentação de métodos não paramétricos nos quais funções quantílica condicionais são ajustadas localmente. Métodos locais que tornam a curva ajustada resistente a valores discrepantes da variável preditora $X$ (métodos robustos) foram também considerados, adaptando as sugestões feitas por Einbeck et al. (2004) no ajuste local da função de regressão. Os procedimentos de ajuste local foram aplicados a um conjunto de dados relacionado à área de Cardiologia, com o objetivo de construir curvas de referência para a freqüência cardíaca média de indivíduos saudáveis em função da sua idade. Os resultados obtidos mostraram que as curvas de referência construídas pelos métodos robustos são mais apropriadas nas regiōes de baixa freqüiência da idade. 


\section{Abstract}

The reference curves are widely used in real problems to evaluate whether the sample units follow, or not, an expected behavior, according to some characteristic of interest. In the medical area, for example, the reference curves, for reflecting the behavior of the healthful individuals, supply a kind of clinical guide to interpret the information of a new patient. The construction of the reference curves involves the estimation of the populational quantiles of response variable $(Y)$ distribution, at different values of predictor variable $(X)$. With the objective to construct reference curves, this work presents some nonparametric regression methods that fit conditional quantiles functions locally. Local quantile regression methods that are robust to outlying predictor variable values are derived by adapting the methodology suggested in Einbeck et al. (2004) in the local fitting of the regression function. These procedures are applied to a data set related to the cardiology area, with the objective to construct reference curves for the average cardiac frequency of healthful individuals as function of their age. The obtained results show that the reference curves constructed by the robust methods are more appropriate in the regions in which the design is sparse. 


\section{Índice}

1 Introdução

2 Regressão polinomial local $\quad 9$

2.1 Introdução . . . . . . . . . . . . . . . . . . . 9

2.2 Aspectos importantes no ajuste polinomial local . . . . . . . . . 13

2.3 Exemplo do ajuste polinomial local . . . . . . . . . . . . . . 21

3 Curvas de referência e Regressão quantílica $\quad 24$

3.1 Introdução . . . . . . . . . . . . . . . . . . . . . . 24

3.2 Regressão quantílica . . . . . . . . . . . . . . . 26

3.2 .1 Regressão quantílica local . . . . . . . . . . . . . . . 29

3.3 Regressão quantílica local resistente a valores discrepantes da variável pre-

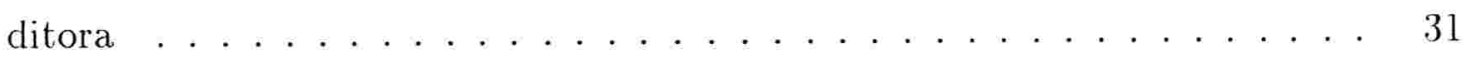

3.3 .1 "Robustificação" fraca . . . . . . . . . . . . . . . 32

3.3 .2 "Robustificação" forte . . . . . . . . . . . . . . 33

3.4 Efeito da "robustificação" no ajuste da função quantílica local . . . . . . . 34

4 Aspectos computacionais no ajuste da função quantílica local $\quad 38$ 
5.1 Apresentação do problema . . . . . . . . . . . . . . 45

6 Considerações finais $\quad 52$

A Variância e Viés assintóticos $\quad 53$

B Rotina para o cálculo do parâmetro de suavização $h$ constante $\quad 55$

$\begin{array}{ll}\text { C Rotina para o ajuste da função quantílica } & 58\end{array}$

C.1 Rotina para o ajuste local da função quantílica . . . . . . . . . . 58

C.2 Rotina para o ajuste local robusto da função quantílica . . . . . . . . . 59 


\section{Capítulo 1}

\section{Introdução}

A análise de regressão é uma metodologia estatística que tem como principal objetivo descrever a associação entre uma variável resposta $Y$ e uma ou mais variáveis preditoras $X_{1}, \ldots, X_{p}$.

Na situação mais simples, na qual é considerada apenas uma variável preditora, o modelo de regressão assume a forma:

$$
Y_{i}=m\left(X_{i}\right)+\varepsilon_{i},
$$

em que $m(x)$ é a função que estabelece a relação funcional entre $Y$ e $X, \varepsilon_{i}$ são erros aleatórios com média zero, não correlacionados e com variância $\sigma_{i}^{2}, i=1, \ldots, n$. Como $\mathrm{E}(Y \mid X=x)=m(x)$, qualquer estimativa de $m(x)$ pode ser vista como uma estimativa desta esperança condicional.

Quando a forma da função $m(x)$ em (1.1) é especificada, exceto por um número finito de paràmetros, dizemos que o modelo de regressão é paramétrico. Por exemplo, se a relação entre $Y$ e $X$ é linear, a função de regressão é da forma $m(x)=\alpha+\beta x$, levando ao modelo $Y_{i}=\alpha+\beta X_{i}+\varepsilon_{i}, i=1, \ldots, n$, onde $\alpha$ e $\beta$ são parâmetros desconhecidos a serem estimados. Possíveis métodos de estimação são o de máxima verossimilhança e o de mínimos quadrados (Neter et al., 1996). 
O primeiro passo para a especificação de $m(x)$ é a construção do diagrama de dispersão de $Y$ e $X$. Como ilustração, consideremos o conjunto de dados fornecidos por Schimidt et al. (1981), no qual são simulados acidentes com motos com o objetivo de avaliar os efeitos físicos e traumatológicos que o impacto desses acidentes pode causar nos motociclistas.

No diagrama de dispersão apresentado na Figura 1.1 estão representados 94 pontos $\left(x_{i}, y_{i}\right)$ correspondentes aos valores observados da Aceleração da cabeça do objeto teste, em $\mathrm{g}^{*}(Y)$ e o Tempo após o impacto do acidente, em milisegundos $(X)$.

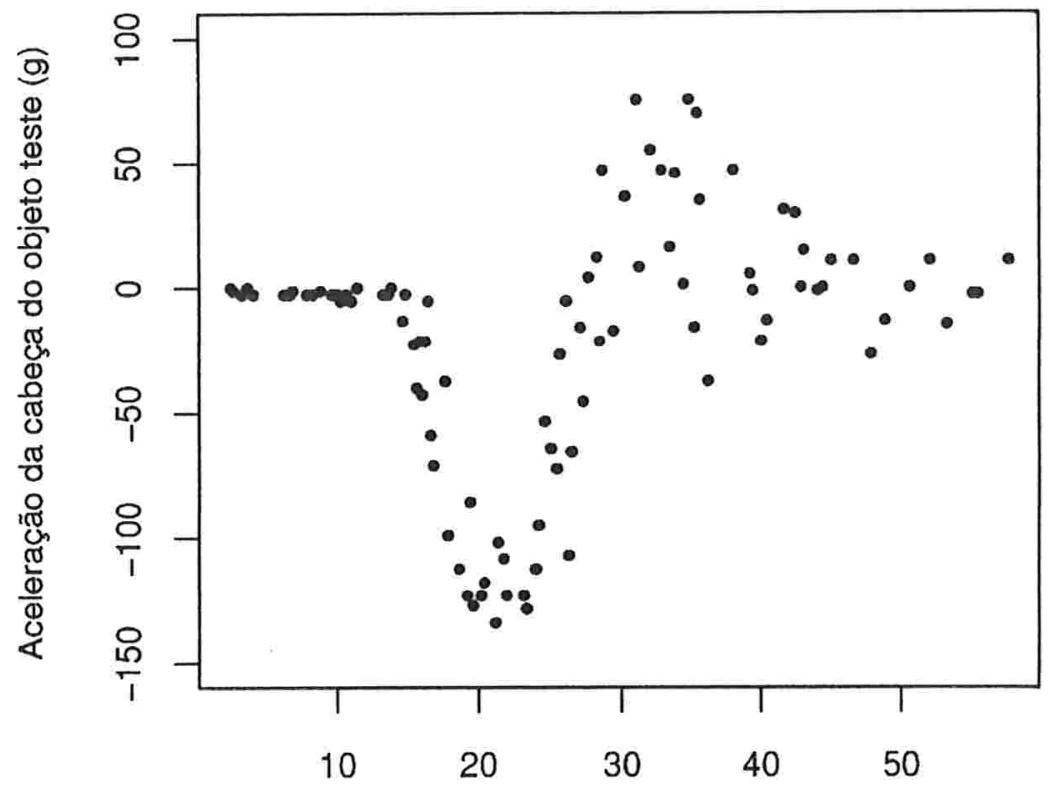

Tempo após o impacto do acidente (milisegundos)

Figura 1.1: Diagrama de dispersão da Aceleração da cabeça do objeto teste (g) e o Tempo após o impacto do acidente (milisegundos).

Uma reta é claramente inapropriada para descrever a relação entre $Y$ e $X$ e uma alternativa é o ajuste de um modelo de regressão polinomial. Modelos polinomiais 
de diferentes graus foram ajustados a esse conjunto de dados e os valores previstos estão representados na Figura 1.2 .

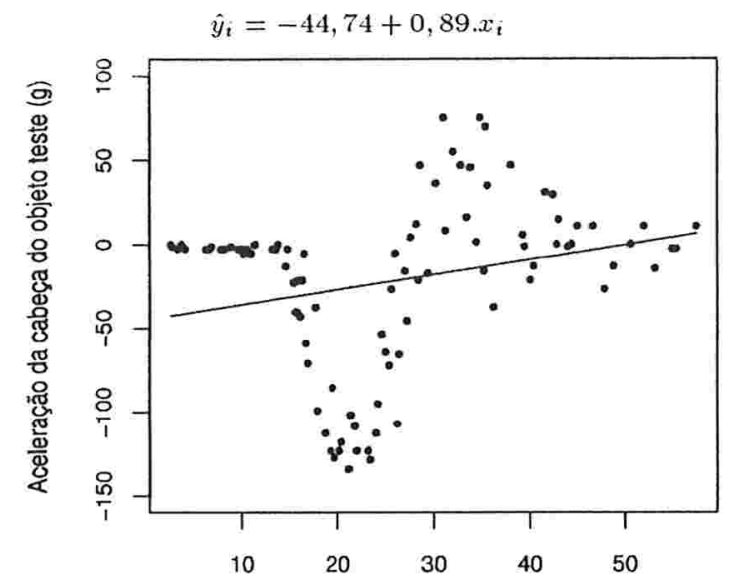

Tempo após o impacto do acidente (milisegundos)

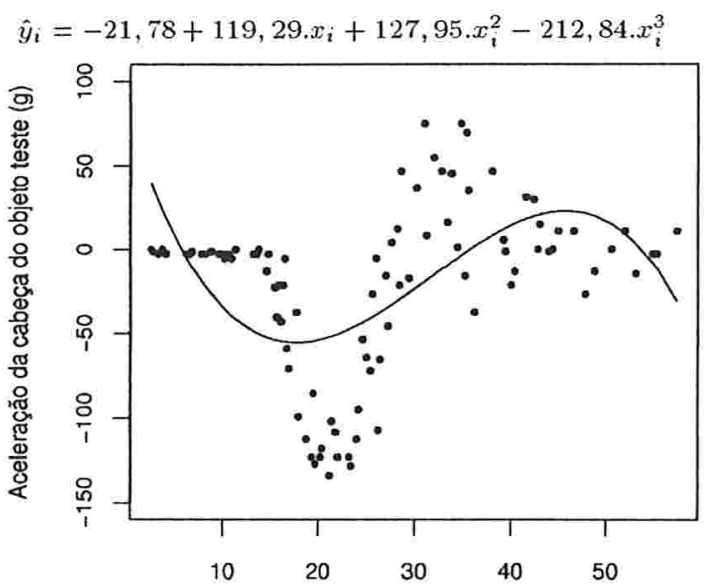

Tempo após o impacto do acidente (milisegundos)

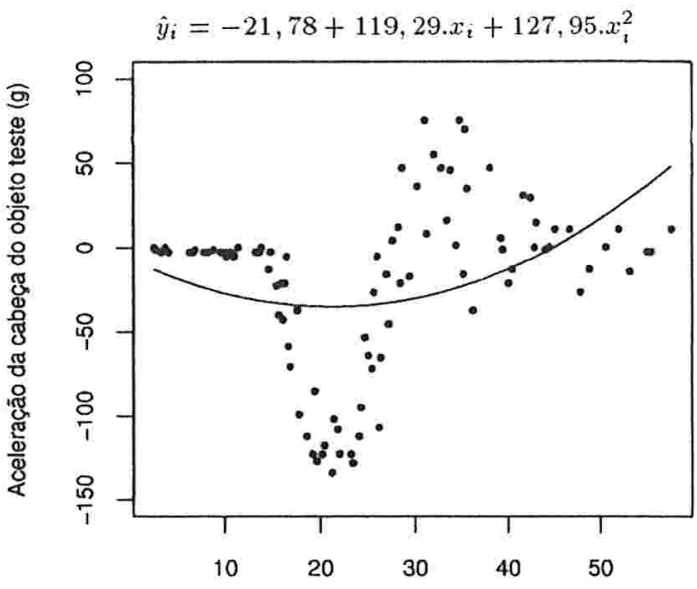

Tempo após o impacto do acidente (milisegundos)

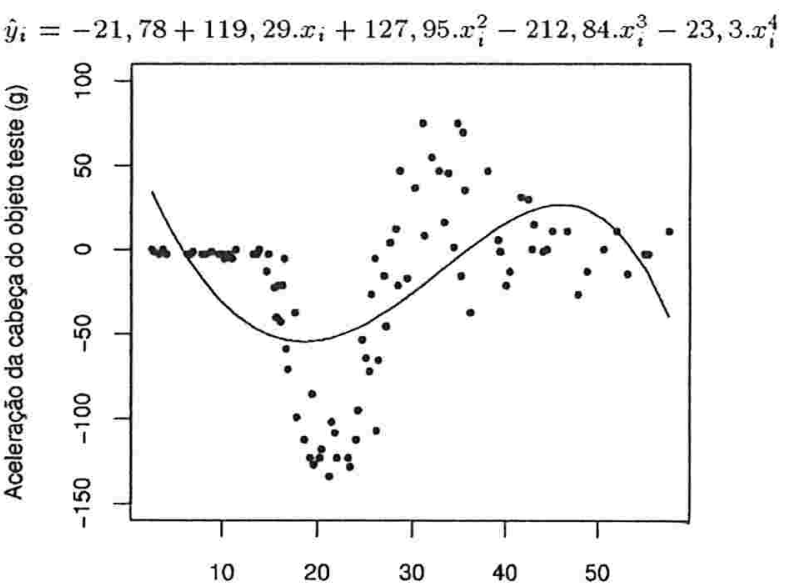

Tempo após o impacto do acidente (milisegundos)

Figura 1.2: Modelos polinomiais ajustados para descrever a relação entre a Aceleração da cabeça do objeto teste (g) e o Tempo após o impacto do acidente (milisegundos).

Notamos que mesmo o ajuste de um polinômio de grau 4 não é adequado para modelar comportamentos locais. A adoção de um modelo de regressão não paramétrico é um procedimento alternativo para este problema (Hastie e Tibshirani, 1990). 
A regressão não paramétrica, ao contrário da paramétrica, não assume um forma especificada para $m(x)$. A relação entre $Y$ e $X$ é definida pelos próprios dados. A única restrição sobre $m(x)$ é que seja suave e que tenha derivadas contínuas até uma determinada ordem fixada.

Nas últimas décadas, houve um acentuado desenvolvimento das técnicas não paramétricas. Alguns métodos não paramétricos de ajuste de curvas, denominados de técnicas de suavização ou ainda, suavizadores, podem ser detalhadamente encontrados em Cleveland (1979), Müller (1988), Nadaraya (1989), Hastie e Tibshirani (1990), Green e Silverman (1994), Fan e Gijbels (1996) entre outros.

O suavizador é uma ferramenta estatística que resume e descreve a tendência de uma variável resposta $Y$ como função de uma ou mais variáveis preditoras $X_{1}, \ldots, X_{p}$. Esse procedimento produz uma estimativa que apresenta uma variabilidade menor que a de $Y$, daí o nome de suavizador ou alisador. Quando a tendência de $Y$ é descrita em função de apenas uma variável $X$, o suavizador é denominado unidimensional. Quando $p$ variáveis preditoras são consideradas simultaneamente, diz-se que o suavizador é multidimensional. Apenas suavizadores unidimensionais são apresentados neste trabalho.

O resultado de um procedimento de suavização consiste de valores ajustados de $Y, \hat{y}_{i}, i=1, \ldots, n$. Os pontos $\left(x_{i}, \hat{y}_{i}\right)$ são representados graficamente resultando na curva ajustada.

De modo geral, os métodos de suavização podem ser classificados em três categorias (Fahrmeir e Tutz, 1996): os que são modelados por funções de base, os penalizados e os locais.

Os suavizadores que estimam $m(x)$ utilizando funções de base, como por exemplo, a regressão spline, assumem que $m(x)$ é uma seqüência de polinòmios por partes de grau $d$ que se unem em determinados valores de $X$ denominados nós ou pontos de quebra. Em geral, é fixado $d=3$ e assume-se que $m(x)$ possui primeira e segunda derivadas 
contínuas nos nós.

Formalmente, dados $K$ nós, $\delta_{1}, \ldots, \delta_{k}$, assume-se que $m(x)$ pertence ao espaço gerado por um conjunto de funções de base $B_{j}(x), j=1, \ldots, k+d+1$. Diferentes funções de base podem ser consideradas. Uma possível escolha é o conjunto de funções baseado na série de potência truncada, como a seguir:

$$
\begin{aligned}
B_{0}(x) & =1, \\
B_{1}(x) & =x, \\
& \vdots \\
B_{d}(x) & =x^{d}, \\
B_{d+1}(x) & =\left(x-\delta_{1}\right)_{+}^{d}, \\
& \vdots \\
B_{k+d+1}(x) & =\left(x-\delta_{k}\right)_{+}^{d},
\end{aligned}
$$

em que $B_{d+1}(x), \ldots, B_{k+d+1}(x)$ é a série de potência truncada com

$$
\left(x-\delta_{i}\right)_{+}^{d}=\left\{\begin{array}{cc}
\left(x-\delta_{i}\right)^{d} & , \text { se } x-\delta_{i} \geqslant 0 \\
0 \quad & \text { se } x-\delta_{i}<0
\end{array}, i=1, \ldots, k .\right.
$$

Usando esta base, a função de regressão $m(x)$ é dada por:

$$
m(x)=\beta_{0}+\beta_{1} x+\cdots+\beta_{d} x^{d}+\sum_{i=1}^{k} \nu_{i}\left(x-\delta_{i}\right)_{+}^{d},
$$

onde $\beta_{0}, \ldots, \beta_{d}, \nu_{1}, \ldots, \nu_{k}$ são parâmetros a serem estimados.

Outras bases podem ser consideradas, como, por exemplo, a base B-spline descrita em de Boor (1978) e Marx e Eilers (1998).

Um problema na utilização da Regressão Spline está na escolha do número e da posição dos nós de forma adequada: um número muito grande de nós fará com que a curva ajustada seja muito ondulada, enquanto que um número reduzido de nós pode levar a curva 
ajustada a não descrever adequadamente o comportamento dos dados, como descrito em Hastie e Tibshirani (1990). A dificuldade na escolha do número de nós pode ser contornada utilizando o suavizador P-Spline que é a combinação de suavizadores que são modelados por funções de base e os penalizados, descrito com detalhes em Marx e Eilers (1998). A Figura 1.3 ilustra as curvas suavizadas por Regressão Spline variando o número de nós utilizando os dados dos motociclistas.

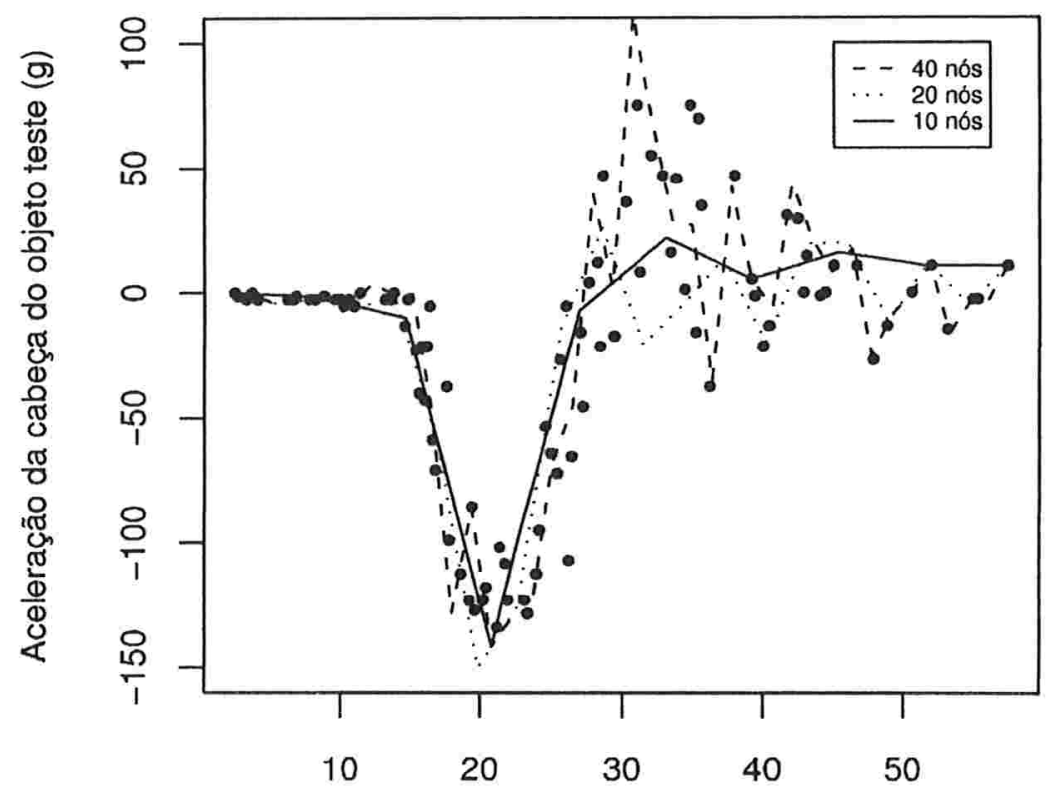

Tempo após o impacto do acidente (milisegundos)

Figura 1.3: Curvas suavizadas por Regressão Spline variando o número de nós.

A segunda classe de suavizadores utiliza um termo de penalização no critério de ajuste da função de regressão $m(x)$. Como exemplo desta classe de suavizadores, pode-se citar o Cubic Spline. Este suavizador procura, entre todas as funções $m(x)$ com primeira e segunda derivadas contínuas no intervalo $[a, b]=\left[x_{(1)}, x_{(n)}\right]$, aquela que minimiza a expressão:

$$
\sum_{i=1}^{n}\left\{Y_{i}-m\left(X_{i}\right)\right\}^{2}+\lambda \int_{a}^{b}\left(m^{\prime \prime}(u)\right)^{2} \mathrm{~d} u, \operatorname{com} \lambda>0
$$


em que $a \leqslant x_{(1)} \leqslant \ldots \leqslant x_{(n)} \leqslant b$, onde $x_{(1)}$ e $x_{(n)}$ são, respectivamente, os valores mínimo e máximo de $X$ na amostra. Uma medida de bondade de ajuste dos dados é dada por $\sum_{i=1}^{n}\left\{Y_{i}-m\left(X_{i}\right)\right\}^{2}$, enquanto que uma medida de suavidade (ondulação) de $m(x)$ é fornecida por $\int_{a}^{b}\left(m^{\prime \prime}(u)\right)^{2} \mathrm{~d} u$. No caso de funções $m(x)$ lineares tem-se $\int_{a}^{b}\left(m^{\prime \prime}(u)\right)^{2} \mathrm{~d} u=0$, enquanto que as funções não lineares estão associados a valores maiores do que zero desta expressão. O parâmetro $\lambda$ controla a relação de ganho e perda entre a bondade de ajuste e a ondulação da curva ajustada: quando $\lambda \rightarrow \infty$, maior peso é dado à segunda parcela da expressão (1.2) produzindo curvas mais suaves, isto é, menos onduladas. Em outro extremo, se $\lambda \rightarrow 0$, essa parcela tem pouca influência e a curva ajustada tende a interpolar os pontos.

Maiores detalhes sobre suavizadores penalizados são obtidos em Schoenberg (1964), Reinsch (1967), Kimeldorf e Wahba (1970, 1971).

A terceira classe de suavizadores, os classificados como locais, ajustam a função de regressão $m(x)$ utilizando as observações da variável preditora $X$ que se encontram na vizinhança de um específico valor $x_{0}$. A vizinhança é definida por intermédio do parâmetro de suavização. O peso atribuído às observações é dado por uma função Kernel, que é uma função densidade de probabilidade, que atribui peso alto para as observações próximas a $x_{0}$ e peso baixo para as observações distantes de $x_{0}$.

Entre os suavizadores classificados como locais podem-se citar o de regressão polinomial local (Fan e Gijbels, 1996), lowess (LOcally WEighted Scatterplot Smoother) (Cleveland, 1979), entre outros.

Neste trabalho nos concentramos no método de regressão polinomial local que é descrito no Capítulo 2. A regressão polinomial local ajusta um polinômio de grau $p$ localmente, em cada vizinhança de $X=x_{0}$ fixado. Esse método de modelagem teve origem no século XIX, quando o meteorologista italiano Schiaparelli (1866) e o matemático americano de Forest (1873) se destacaram entre os primeiros a trabalhar com polinômios 
locais.

No Capítulo 3 adotamos uma aplicação do método de ajuste polinomial local para construir curvas de referência (Harris e Boyd, 1995). Como exemplo desta metodologia podem-se citar as curvas de referência para o peso e estatura de crianças, bastante conhecidas na área de Pediatria, que são construídas em função da idade, para cada sexo. Dados, então, a idade e o sexo de uma nova criança, o valor de seu peso e de sua estatura podem ser avaliados em relação ao restante da população do mesmo sexo e idade. Nesta situação, tem-se interesse em estimar, não a esperança condicional de $Y$ dado $X=x$, mas os quantis condicionais de $Y$. Esses quantis são dados pelas funções quantílicas condicionais e envolvem a estimação de quantis populacionais da distribuição da variável resposta $Y$, a cada valor $x$ da variável preditora $X$.

Nesse capítulo são apresentados alguns conceitos sobre a função quantílica condicional, assim como o procedimento de estimação desta função utilizando o método de ajuste local. Métodos locais para o ajuste da função quantílica que tornam a curva ajustada resistente a valores discrepantes da variável preditora são também considerados.

Os aspectos computacionais utilizados no ajuste local da função quantílica são abordados no Capítulo 4.

Os procedimentos de ajuste local descritos no Capítulo 3 são aplicados a um conjunto de dados relacionado à área de Cardiologia, conforme descrito no Capítulo 5. O objetivo do estudo utilizado nessa aplicação é construir curvas de referência para a freqüência cardíaca média de indivíduos saudáveis considerando sua idade e sexo.

Algumas considerações finais sobre o trabalho e propostas para estudos futuros são feitas no Capítulo 6 . 


\section{Capítulo 2}

\section{Regressão polinomial local}

\subsection{Introdução}

Neste capítulo são apresentados alguns resultados de um dos métodos mais utilizados de estimação não paramétrica da função de regressão: o método polinomial local. Uma das maiores vantagens deste método é seu bom comportamento nas regiões de fronteira. Esta técnica de suavização, em uma abordagem unidimensional, é aplicada ao conjunto de dados dos motociclistas descrito no Capítulo 1.

Considere uma amostra aleatória $\left(X_{1}, Y_{1}\right), \ldots,\left(X_{n}, Y_{n}\right)$ selecionada da população $(X, Y)$. Assumimos que os dados são gerados a partir do modelo:

$$
Y=m(X)+\sigma(X) \varepsilon
$$

em que $m(x)=\mathrm{E}(Y \mid X=x)$ é a função de regressão, $\sigma^{2}(x)=\operatorname{Var}(Y \mid X=x), \mathrm{E}(\varepsilon)=0$, $\operatorname{Var}(\varepsilon)=1$ e $X$ e $\varepsilon$ são independentes.

Supondo que, para todo ponto $x=x_{0}$, as $(p+1)$-ésimas derivadas da função $m(x)$ neste ponto existam, e utilizando a expansão de Taylor podemos aproximar a função de regressão não conhecida $m(x)$, para valores da variável $X$ na vizinhança de $x_{0}$, por um 
polinômio de grau $p$, ou seja:

$$
\begin{aligned}
m(x) \approx & m\left(x_{0}\right)+m^{\prime}\left(x_{0}\right)\left(x-x_{0}\right)+\frac{m^{\prime \prime}\left(x_{0}\right)}{2 !}\left(x-x_{0}\right)^{2}+\cdots+\frac{m^{(p)}\left(x_{0}\right)}{p !}\left(x-x_{0}\right)^{p}= \\
= & \sum_{j=0}^{p} \beta_{j}\left(x-x_{0}\right)^{j},
\end{aligned}
$$

com

$$
\beta_{j}=\frac{m^{(j)}\left(x_{0}\right)}{j !}
$$

Assim, por (2.2), quando $x=x_{0}$, a função de regressão é dada por:

$$
m(x) \approx m\left(x_{0}\right)=\beta_{0}
$$

De (2.3), segue que a $j$-ésima derivada de $m(x)$ no ponto $x_{0}$ é $m^{(j)}\left(x_{0}\right)=j ! \beta_{j}$.

O polinômio $m(x)$ em (2.2) pode ser ajustado localmente, encontrando valores do vetor $\boldsymbol{\beta}=\left(\beta_{0}, \ldots, \beta_{p}\right)^{T}$, que tornem mínima a expressão:

$$
\sum_{i=1}^{n} 1\left\{Y_{i}-\sum_{j=0}^{p} \beta_{j}\left(X_{i}-x_{0}\right)^{j}\right\} K_{h}\left(X_{i}-x_{0}\right),
$$

em que l(.) é a função de perda escolhida, $K_{h}()=.\frac{1}{h} K(\dot{\bar{h}}) \operatorname{com} K($.$) sendo a função Kernel$ que atribui pesos aos dados e $h$, sendo $h>0$, é o parâmetro de suavização, aqui também denominado tamanho da vizinhança a ser considerado em cada ajuste local.

No caso da função de perda assumir a forma $l(t)=t^{2}$, a expressão (2.4) se reduz ao ajuste local pelo método de mínimos quadrados ponderados, resultando na regressão polinomial local propriamente dita. O processo de minimização da expressão (2.4) é, então, equivalente a resolver o problema:

$$
\min _{\beta}(\mathrm{y}-\mathbf{X} \boldsymbol{\beta})^{T} \mathbf{W}(\mathrm{y}-\mathbf{X} \boldsymbol{\beta})
$$


com

$$
\begin{gathered}
\mathbf{y}=\left(\begin{array}{c}
Y_{1} \\
Y_{2} \\
\vdots \\
Y_{n}
\end{array}\right), \mathbf{X}=\left(\begin{array}{cccc}
1 & \left(X_{1}-x_{0}\right) & \ldots & \left(X_{1}-x_{0}\right)^{p} \\
1 & \left(X_{2}-x_{0}\right) & \ldots & \left(X_{2}-x_{0}\right)^{p} \\
\vdots & \vdots & \vdots & \vdots \\
1 & \left(X_{n}-x_{0}\right) & \ldots & \left(X_{n}-x_{0}\right)^{p}
\end{array}\right), \\
\boldsymbol{\beta}=\left(\begin{array}{c}
\beta_{0} \\
\beta_{1} \\
\vdots \\
\beta_{p}
\end{array}\right) e \mathbf{W}=\operatorname{diag}\left\{K_{h}\left(X_{i}-x_{0}\right)\right\} .
\end{gathered}
$$

Portanto, a solução de (2.5) é:

$$
\hat{\boldsymbol{\beta}}=\left(\mathbf{X}^{T} \mathbf{W X}\right)^{-1} \mathbf{X}^{T} \mathbf{W} \mathbf{y}
$$

As expressões da esperança, do viés e da variância do estimador $\hat{\boldsymbol{\beta}}$, condicional a. $\left(X_{1}, \ldots, X_{n}\right)^{T}=\mathbb{X}$, são obtidas de $(2.6)$ e dadas por:

$$
\begin{aligned}
\mathrm{E}(\hat{\boldsymbol{\beta}} \mid \mathbb{X}) & =\left(\mathbf{X}^{T} \mathbf{W X}\right)^{-1} \mathbf{X}^{T} \mathbf{W} \boldsymbol{m}=\boldsymbol{\beta}+\left(\mathbf{X}^{T} \mathbf{W X}\right)^{-1} \mathbf{X}^{T} \mathbf{W r}, \\
\operatorname{Viés}(\hat{\boldsymbol{\beta}} \mid \mathbb{X}) & =\left(\mathbf{X}^{T} \mathbf{W X}\right)^{-1} \mathbf{X}^{T} \mathbf{W r} \\
\operatorname{Var}(\hat{\boldsymbol{\beta}} \mid \mathbb{X}) & =\left(\mathbf{X}^{T} \mathbf{W X}\right)^{-1}\left(\mathbf{X}^{T} \Sigma \mathbf{X}\right)\left(\mathbf{X}^{T} \mathbf{W X}\right)^{-1},
\end{aligned}
$$

onde:

$$
\begin{aligned}
\boldsymbol{m} & =\left\{m\left(X_{1}\right), \cdots, m\left(X_{n}\right)\right\}^{T}, \\
\boldsymbol{\beta} & =\left\{m\left(x_{0}\right), \cdots, \frac{m^{(p)}\left(x_{0}\right)}{p !}\right\}^{T}, \\
\mathrm{r} & =\boldsymbol{m}-\mathbf{X} \boldsymbol{\beta}, \\
\Sigma & =\operatorname{diag}\left\{\Lambda_{h}^{-2}\left(X_{i}-x_{0}\right) \sigma^{2}\left(X_{i}\right)\right\} .
\end{aligned}
$$


As expressões exatas do viés e da variância em (2.7) e (2.8) não são diretamente aplicáveis pois dependem das quantidades desconhecidas $\mathrm{r}$ e $\Sigma$. Desta forma, existe a necessidade de serem obtidas expressões aproximadas para representá-las.

Assumindo que, para valores da variável $X$ na vizinhança de cada ponto $x_{0}$ fixado, a função densidade de $X, f\left(x_{0}\right)$, é estritamente positiva e a $(p+1)$-ésima derivada de $m($.$) dada por m^{(p+1)}(),. f($.$) e \sigma^{2}($.$) são funções contínuas nesta vizinhança, e ainda$ que $h \rightarrow 0$ e $n h \rightarrow \infty$, Ruppert e Wand (1994) obtiveram as expressões assintóticas de primeira ordem para a variância e o viés do estimador da $j$-ésima derivada de $m(x)$ no ponto $x_{0}, \hat{m}^{(j)}\left(x_{0}\right)$. Estas expressões são apresentadas no Apêndice A.

No caso particular, em que $x=x_{0}$, vimos que $m(x) \approx m\left(x_{0}\right)$ e a expressão do viés assintótico condicional de $\hat{m}\left(x_{0}\right)$ assume a forma:

$$
\mathrm{E}\left[\hat{m}\left(x_{0}\right)-m\left(x_{0}\right)\right]=\frac{h^{p+1} m^{(p+1)}\left(x_{0}\right)}{(p+1) !} \mu_{p+1}(K)+o_{p}\left(h^{p+1}\right),
$$

quando $p$ é ímpar, e quando $p$ é par, é dado por:

$$
\begin{aligned}
\mathrm{E}\left[\hat{m}\left(x_{0}\right)-m\left(x_{0}\right)\right]= & {\left[\frac{h^{p+2} m^{(p+1)}\left(x_{0}\right) f^{\prime}\left(x_{0}\right)}{(p+1) ! f\left(x_{0}\right)}+\frac{h^{p+2} m^{(p+2)}\left(x_{0}\right)}{(p+2) !}\right] \mu_{p+2}(K)+} \\
& +o_{p}\left(h^{p+2}\right),
\end{aligned}
$$

onde $m^{(j)}\left(x_{0}\right)$ é a $j$-ésima derivada de $m(x)$ no ponto $x_{0}, f\left(x_{0}\right)$ é a função densidade de $X$ no ponto $x_{0}$ e $\mu_{q}(K)=\int u^{q} K(u) \mathrm{d} u$, que depende somente da função Kernel $K($.$) .$

A variância assintótica condicional de $\hat{m}\left(x_{0}\right)$ é dada por:

$$
\operatorname{Var}\left[\hat{m}\left(x_{0}\right)\right]=\frac{\sigma^{2}\left(x_{0}\right)}{n h f\left(x_{0}\right)} \int K^{2}(u) \mathrm{d} u+o_{p}\left((n h)^{-1}\right)
$$

onde $\sigma^{2}\left(x_{0}\right)$ é a variância condicional de $Y$ dado $X=x_{0}, h$ é o parâmetro de suavização, $K($.$) é a função Kernel e f\left(x_{0}\right)$ é a função densidade de $X$ no ponto $x_{0}$. 


\subsection{Aspectos importantes no ajuste polinomial local}

No ajuste local da função de regressão existem aspectos importantes a serem discutidos: a determinação do parâmetro de suavização $h$, a escolha da função Kernel $K($.$) a ser utilizada e o grau p$ dos polinômios ajustados localmente.

A escolha do parâmetro de suavização $h$ é o aspecto mais importante a ser considerado no ajuste polinomial local, por permitir diferentes níveis de suavização.

Para valores pequenos de $h$, somente as observações imediatamente próximas de $x_{0}$ serão influentes; para grandes valores de $h$, as observações distantes de $x_{0}$ também influenciarão na estimativa local. De maneira geral, quando $h \rightarrow 0$, o resultado do ajuste polinomial tende a interpolar os dados, levando a um modelo mais complexo. Quando $h \rightarrow \infty$ há um ajuste global de um polinômio de grau $p$, resultando em um modelo mais simples. Por este motivo, diz-se que o $h$ controla a complexibilidade do modelo ajustado.

É importante notar que o viés de $\hat{m}(x)$, quando $x=x_{0}$, dado nas expressões $(2.9)$ e (2.10) envolve o parâmetro de suavização $h$ no numerador, enquanto que a variância de $\hat{m}(x)$ em (2.11), apresenta o parâmetro $h$ no denominador. Por esse fato, quando $h \rightarrow 0 \mathrm{e}$ $n h \rightarrow \infty$, o viés torna-se menor e, em contrapartida, a variância maior.

A escolha do parâmetro de suavização $h$ deve ser feita com bastante cautela. Pode-se optar por um $h$ constante, também conhecido como $h$ global, ou por um $h$ variável. Na classe do $h$ variável, uma distinção deve ser feita entre o $h$ variável local e o $h$ variável global: o $h$ variável local, $h\left(x_{0}\right)$, varia de acordo com a localização do ponto $x_{0}$, enquanto que o $h$ variável global, $h\left(X_{i}\right)$, muda com as observações.

A literatura sobre a escolha teórica do $h$ variável global é bastante ampla e está resumida em Fan e Gijbels (1992). Neste trabalho nos concentramos na escolha do $h$ variável local e do $h$ constante.

O valor teórico ótimo do $h$ variável local para estimar $m^{(j)}\left(x_{0}\right)$ é obtido minimi- 
zando o Erro Quadrático Médio condicional a $\left(X_{1}, \ldots, X_{n}\right)^{T}=\mathbb{X}$, dado por:

$$
\left[\operatorname{Viés}\left\{\hat{m}^{(j)}\left(x_{0}\right) \mid \mathbb{X}\right\}\right]^{2}+\operatorname{Var}\left\{\hat{m}^{(j)}\left(x_{0}\right) \mid \mathbb{X}\right\} \text {. }
$$

Essa escolha teórica pode ser aproximada pelo $h$ variável local assintoticamente ótimo, isto é, o $h$ que minimiza o Erro Quadrático Médio Assintótico condicional obtido das expressões (A.3) e (A.4). Esse processo de minimização resulta em:

$$
h_{\mathrm{opt}}\left(x_{0}\right)=\mathrm{C}_{j, p}(K)\left[\frac{\sigma^{2}\left(x_{0}\right)}{\left\{m^{(p+1)}\left(x_{0}\right)\right\}^{2} f\left(x_{0}\right)}\right]^{1 /(2 p+3)} n^{-1 /(2 p+3)},
$$

$\operatorname{com} \sigma^{2}\left(x_{0}\right)$ e $f\left(x_{0}\right)$ definidos como em $(2.11)$ e $C_{j, p}(K)$ uma constante que depende somente de $j, p$ e da função Kernel $K($.$) , sendo dada por:$

$$
\mathrm{C}_{j, p}(K)=\left[\frac{(p+1) !^{2}(2 j+1) \int K_{j}^{*^{2}}(u) \mathrm{d} u}{2(p+1-j)\left\{\int u^{p+1} K_{j}^{*}(u) \mathrm{d} u\right\}^{2}}\right]^{1 /(2 p+3)},
$$

em que $K_{j}^{*}($.$) é a função Kernel equivalente descrita em Ruppert e Wand (1994). Essa$ função é obtida considerando uma expressão equivalente à (2.6) para o j-ésimo elemento do vetor $\hat{\boldsymbol{\beta}}, \hat{\beta}_{j}, j=0, \ldots, p$, dada por:

$$
\hat{\beta}_{j}=\frac{1}{n h^{j+1} f\left(x_{0}\right)} \sum_{i=1}^{n} K_{j}^{*}\left(\frac{X_{i}-x_{0}}{h}\right) Y_{i}\left\{1+o_{p}(1)\right\},
$$

onde

$$
\begin{aligned}
K_{j}^{*}(u) & =e_{j+1}^{T} S^{-1}\left(1, u, \ldots, u^{p}\right)^{T} K(u), \text { sendo } K_{j}^{*}(.) \text { a função Kernel equivalente, } \\
e_{j+1}^{T} & =(0, \ldots, 0,1,0, \ldots, 0) \text { é o vetor com } 1 \text { na }(j+1) \text {-ésima posição e } 0 \text { nas demais, } \\
S & =\left(\mu_{j+l}\right)_{0 \leq j, l \leq p}, \\
\mu_{j} & =\int u^{j} K(u) \mathrm{d} u .
\end{aligned}
$$

A Tabela 2.1 apresenta os valores da constante $C_{j, p}(K)$ para alguns valores de $j, p$ e funções Kernel comumente utilizadas. 
Tabela 2.1: Valores da Constante $C_{j, p}(K)$ para alguns valores de $j, p$ e funções Kernel.

\begin{tabular}{cccccc}
\hline \hline & \multicolumn{5}{c}{ Função Kernel } \\
\cline { 3 - 6 }$j$ & $p$ & Normal & Uniforme & Epanechnikov & Tricúbica \\
\hline \hline 0 & 1 & 0,776 & 1,351 & 1,719 & 2,312 \\
0 & 3 & 1,161 & 2,813 & 3,243 & 3,987 \\
1 & 2 & 0,884 & 1,963 & 2,275 & 2,869 \\
2 & 3 & 1,006 & 2,604 & 2,893 & 3,503 \\
\hline \hline
\end{tabular}

Fonte: Fan e Gijbels (1995)

Para a determinação do $h$ constante, é considerada uma função de perda global, dada pelo Erro Quadrático Médio Ponderado Integrado condicional, dado por:

$$
\int\left(\left[\operatorname{Viés}\left\{\hat{m}^{(j)}(x) \mid \mathbb{X}\right\}\right]^{2}+\operatorname{Var}\left\{\hat{m}^{(j)}(x) \mid \mathbb{X}\right\}\right) w(x) \mathrm{d}(x),
$$

com $w($.$) sendo uma função de peso não negativa estabelecida a priori. Utilizando as$ expressões assintóticas da variância e do viés dadas em (A.3) e (A.4) respectivamente, o valor assintoticamente ótimo para $h$ contante que minimiza (2.14) é:

$$
h_{\mathrm{opt}}=\mathrm{C}_{j, p}(K)\left[\frac{\int \sigma^{2}(x) w(x) / f(x) \mathrm{d} x}{\int\left\{m^{(p+1)}(x)\right\}^{2} w(x) \mathrm{d} x}\right]^{1 /(2 p+3)} n^{-1 /(2 p+3)},
$$

$\operatorname{com} \mathrm{C}_{j, p}(K)$ definido em (2.13).

Note que a expressão de $h_{\mathrm{opt}}$ em (2.15), assim como a de $h_{\mathrm{opt}}\left(x_{0}\right)$ em $(2.12)$ contém as quantidades desconhecidas $\sigma^{2}(),. m^{(p+1)}($.$) e f($.$) que necessitam ser estimadas.$ Por esse motivo, sāo necessários procedimentos numéricos para a seleção do valor ótimo para o paràmetro de suavização. Uma das maneiras de contornar essa situação é utilizar o método Plug-in descrito em Ruppert et al. (1995) e implementado no Software R. Neste 
método as quantidades desconhecidas são estimadas iterativamente e então substituídas na expressão (2.15). Assim sendo, os estimadores preliminares de $f(),. m^{(p+1)}($.$) e \sigma^{\mathfrak{s}}($.$) ,$ obtidos utilizando um parâmetro de suavização inicial $\left(h_{1}\right)$, são substituídos em (2.15), resultando em um segundo valor para o parâmetro de suavização $h\left(h_{2}\right)$. Este valor $h_{2}$ é utilizado no cálculo de $\hat{f}(),. \hat{m}^{(p+1)}($.$) e \hat{\sigma}^{2}($.$) para futura obtenção do h_{3}$, e assim, o algoritmo é executado de maneira recursiva até a sua convergência. Existem muitas variações do método Plug-in para regressão local na literatura estatística, considerando, por exemplo, diferentes formas de estimação de $f(),. m^{(p+1)}($.$) e \sigma^{2}($.$) , conforme apresentam Gasser$ et al. (1991).

Uma outra maneira de determinação do parâmetro de suavização $h$ contante é por intermédio dos procedimentos apresentados por Fan e Gijbels (1995) que sugeriram o ajuste global de um polinômio de grau $(p+3)$ aos dados, gerando o ajuste paramétrico:

$$
\breve{m}(x)=\breve{\alpha}_{0}+\cdots+\breve{\alpha}_{p+3} x^{p+3} .
$$

Conforme assumido pelos autores $\sigma^{2}(x)$ como sendo constante para todo $x$ e igual a $\sigma^{2}$, o quadrado médio dos resíduos do modelo ajustado em (2.16) é considerado como uma estimativa deste parâmetro e denotado por $\breve{\sigma}^{2}$.

Supondo que estamos interessados em estimar a $j$-ésima derivada da função de regressão, $m^{(j)}(x)$, no intervalo $[a, b]$, tomando a função de peso $w(x)=f(x) I_{[a, b]}(x)$ e substituindo $m^{(p+1)}(x)$ e $\sigma^{2}(x)$ em $(2.15)$ por $\breve{m}^{(p+1)}(x)$ e $\breve{\sigma}^{2}$ respectivamente, obtemos a seguinte expressão aproximada para o $h$ constante em (2.15):

$$
h_{\text {aprox }}=\mathrm{C}_{j, p}(K)\left[\frac{\breve{\sigma}^{2}(b-a)}{\int_{a}^{b}\left\{\breve{m}^{(p+1)}(x)\right\}^{2} f(x) \mathrm{d} x}\right]^{1 /(2 p+3)} n^{-1 /(2 p+3)}
$$

O denominador de (2.17) pode ser aproximado por:

$$
n^{-1} \sum_{i=1}^{n}\left\{\breve{m}^{(p+1)}\left(X_{i}\right)\right\}^{2} I_{[a, b]}\left(X_{i}\right) \text {. }
$$


Assim procedendo, o valor aproximado do parâmetro de suavização ótimo é:

$$
h_{\text {aprox }}=\mathrm{C}_{j, p}(K)\left[\frac{\breve{\sigma}^{2}(b-a)}{\sum_{i=1}^{n}\left\{\breve{m}^{(p+1)}\left(X_{i}\right)\right\}^{2} I_{[a, b]}\left(X_{i}\right)}\right]^{1 /(2 p+3)},
$$

com

$$
\breve{m}^{(p+1)}\left(X_{i}\right)=(p+1) !\left\{\breve{\alpha}_{p+1}+(p+2) \breve{\alpha}_{p+2} X_{i}+(p+2)(p+3) \breve{\alpha}_{p+3} \frac{X_{i}^{2}}{2}\right\} .
$$

Este procedimento para a obtenção de um valor aproximado do $h$ constante deve ser utilizado sob certas condições, quando por exemplo, não se notar o aparecimento de freqüências alternadas no comportamento dos dados através do diagrama de dispersão, o que tornaria a estimativa $\breve{\sigma}^{2}$ de $\sigma^{2}$ não apropriada.

No caso em que se desejar ajustar a função de regressão utilizando localmente polinômios de primeiro grau e o parâmentro de suavização h constante, Fan e Gijbels (1995) sugerem o uso do parâmetro de suavização $h$ constante $=1,5 \cdot h_{\text {aprox }}$.

Uma rotina computacional para o cálculo de $h_{\text {aprox }}$, dado em (2.18), foi criada no Software R e é apresentada no Apêndice B. Essa rotina é utilizada na Seção 2.3 em um dos exemplos do ajuste polinomial local.

A escolha da função Kernel $K($.$) também é outro aspecto a ser considerado no$ ajuste polinomial local. Como visto em Härdle (1990), diferentes funções do tipo Kernel podem ser utilizadas no ajuste polinomial local, como por exemplo, as apresentadas na Tabela 2.2 . 
Tabela 2.2: Exemplos de Funções Kernel.

\begin{tabular}{cc}
\hline \hline Função Kernel & $K(u)$ \\
\hline \hline Uniforme & $\frac{1}{2} \mathrm{I}(|u| \leqslant 1)$ \\
Triangular & $(1-|u|) \mathrm{I}(|u| \leqslant 1)$ \\
Epanechnikov & $\frac{3}{4}\left(1-u^{2}\right) \mathrm{I}(|u| \leqslant 1)$ \\
Tricúbica & $\left(1-|u|^{3}\right)^{3} \mathrm{I}(|u| \leqslant 1)$ \\
Normal & $\frac{1}{\sqrt{2 \pi}} \exp \left(-\frac{1}{2} u^{2}\right)$ \\
Cosseno & $\frac{\pi}{4} \cos \left(\frac{\pi}{2} u\right) \mathrm{I}(|u| \leqslant 1)$ \\
\hline \hline
\end{tabular}

I(A) é a função indicadora no conjunto A

Fonte: Härdle (1990)

Nas Figuras 2.1 e 2.2 podemos observar as representações gráficas das Funções Kernel: Uniforme, Triangular, Epanechnikov, Tricúbica, Normal e Cosseno. Foram utilizados valores de $u$ gerados por uma variável aleatória com distribuição Uniforme no intervalo $[-1,1]$. 


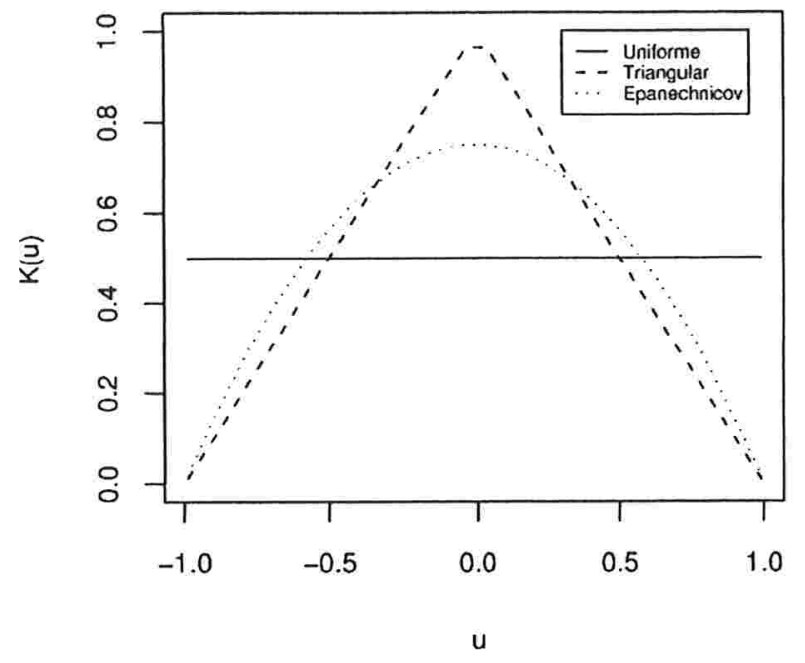

Figura 2.1: Funções Kernel Uniforme, Triangular e Epanechnikov.

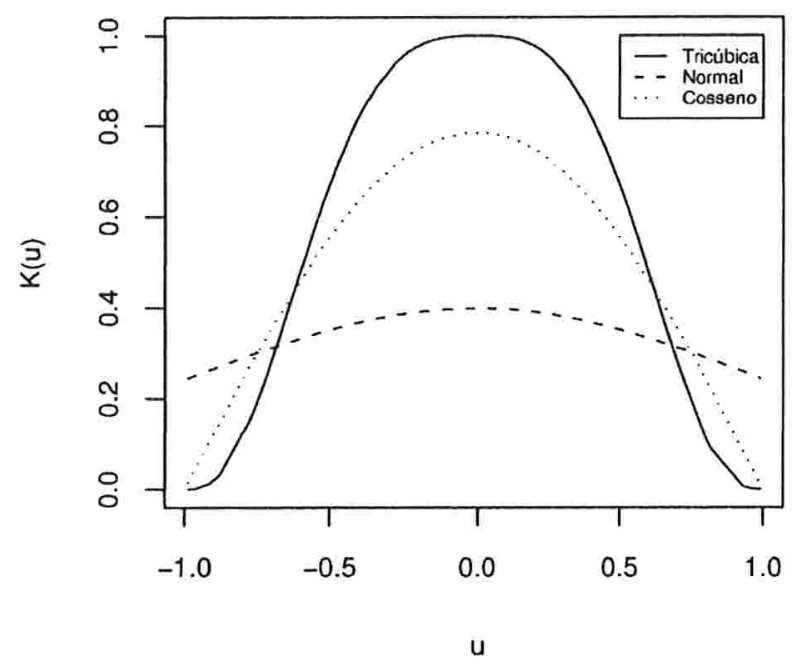

Figura 2.2: Funções Kernel Tricúbica, Normal e Cosseno.

Segundo Fan et al. (1995), para qualquer valor de $p$ e $j$, a função Kernel considerada ótima é a Epanechnikov, por minimizar o erro quadrático médio assintótico condicional do ajuste polinomial local. É importante salientar que a escolha da função Kernel é relativamente pouco importante comparada com a escolha do parâmetro de suavização $h$.

O grau $p$ dos polinòmios ajustados localmente necessita também ser fixado. $\mathrm{O}$ ajuste polinomial de alto grau leva a uma redução do viés, mas por outro lado, aumenta. 
a variabilidade causada pelo acréscimo de mais parâmetros locais. Intuitivamente é preferível a utilização do ajuste local constante ou linear quando for observada localmente, no diagrama de dispersão, nenhuma ou pouca tendência. Se existirem regiões com picos ou vales, o ajuste local quadrático ou cúbico é recomendado.

Na situação particular em que se deseja ajustar um polinômio local de grau $p$ para estimar a $j$-ésima derivada da função de regressão no ponto $x_{0}, m^{(j)}\left(x_{0}\right)$, é importante ressaltar duas situações que envolvem o viés assintótico condicional de $\hat{m}^{(j)}\left(x_{0}\right)$, dado na expressão (A.2):

- Quando $(p-j)$ é ímpar, o viés é da ordem $h^{p+1-j}$, além de não depender da densidade de $X, f(x)$;

- Para $(p-j)$ par, o viés depende de $f(x)$ e é da ordem $h^{p+2-j}$.

Este fato confirma a redução da ordem do viés quando um ajuste polinomial de grau mais alto é adotado.

Outro fato importante é que a ordem da variância assintótica condicional associada ao ajuste local é de $n^{-1} h^{-(1+2 j)}$, não sendo assim influenciada pelo grau do polinômio (ver expressão A.1).

Estas considerações em relação à ordem do viés e da variância assintóticos condicionais, torna evidente a preferência por polinômios de grau ímpar no ajuste local da função de regressão $m(x)$. Apesar do ajuste polinomial de grau $q$ ímpar introduzir um parâmetro extra na comparação com um ajuste de grau $(q-1)$ par, não há aumento da variabilidade, além de ocorrer redução do viés. Essas e outras considerações sobre a preferência de ordem ímpar no ajuste polinomial local podem ser encontrados em Fan (1992). 


\subsection{Exemplo do ajuste polinomial local}

A seguir o método de ajuste polinomial local é ilustrado utilizando os dados dos motociclistas descritos no Capítulo 1.

O diagrama de dispersão de $Y$ e $X$ ilustrado na Figura 2.3 apresenta os ajustes polinomiais locais considerando como função Kernel a Epanechnicov, utilizando polinômios de primeiro grau e considerando diferentes valores do parâmetro de suavização $h$, que foram fixados por meio de inspeção visual do diagrama de dispersão. A curva ajustada considerando $h=10$ não se adapta aos picos e aos vales adequadamente. Quando $h$ é reduzido para 2,5 a curva ajustada torna-se mais ondulada (menos suave), e consegue descrever melhor o comportamento dos dados (menor viés). Reduzindo ainda mais o valor de $h$ para 0,5 , obtém-se uma curva muito ondulada, que não parece representar a verdadeira. tendência dos dados.

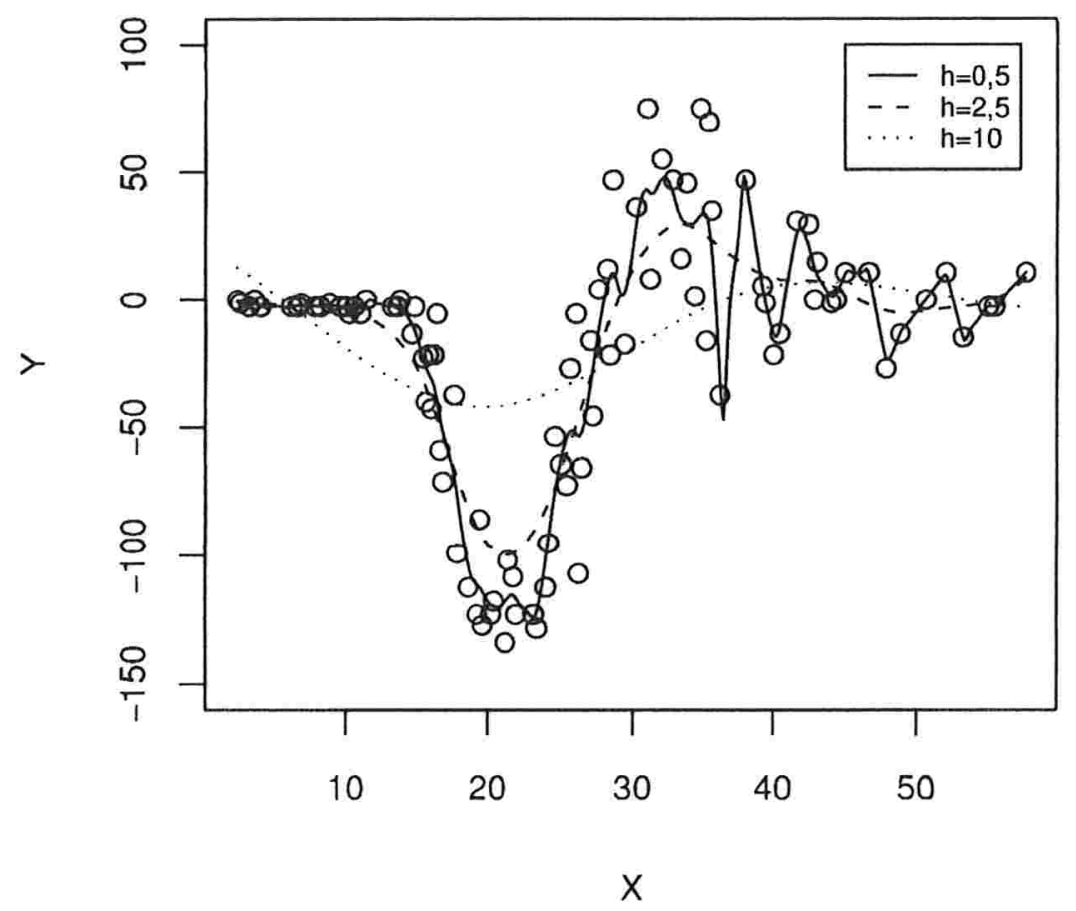

Figura 2.3: Curvas ajustadas pelo método de regresão polinomial local com diferentes valores de $h$. 
A Figura 2.4 apresenta os ajustes polinomiais locais considerando como função Kernel a Epanechnicov, o parâmetro de suavização $h=1,8$ obtido através do método Plugin, e variando o grau dos polinômios a serem ajustados localmente. As curvas ajustadas apresentam comportamentos muito semelhantes, sendo que as curvas utilizando polinômios de segundo e terceiro graus são indistinguíveis visualmente.

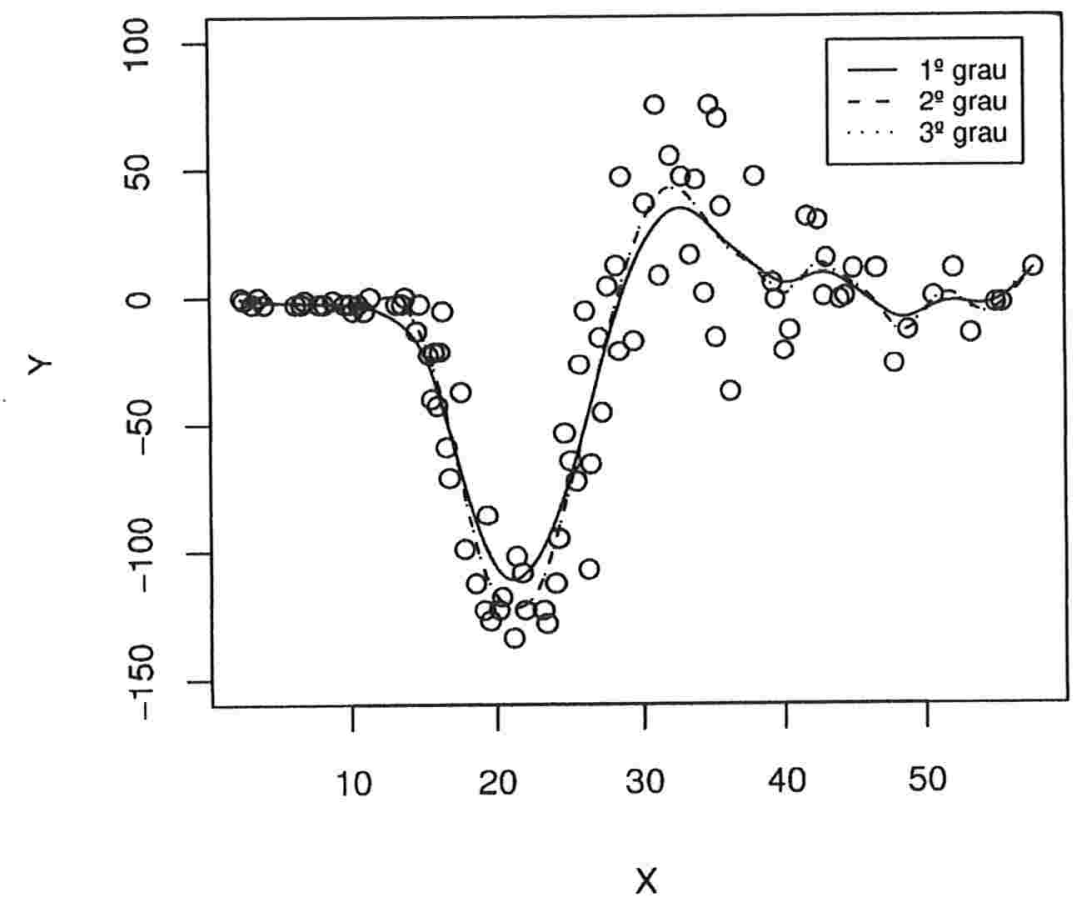

Figura 2.4: Curvas ajustadas pelo método de regressão polinomial local utilizando polinômios de diferentes graus.

O ajuste local, ilustrado na Figura 2.5, foi feito utilizando polinômios de primeiro grau, a função Kernel Epanechnikov e o parâmetro de suavização $h$ constante igual a 0,06, obtido de (2.18) por intermédio da rotina computacional criada com este objetivo (ver Apêndice B). Observe que a curva obtida é bastante ondulada, não sendo compatível à variabilidade dos dados, sugerindo que o tamanho da vizinhança fixado não é adequado. Isto provavelmente ocorreu devido ao fato deste banco de dados não satisfazer às condições dadas na Seção 2.2 para a utilização adequada do $h_{\text {aprox }}$. 


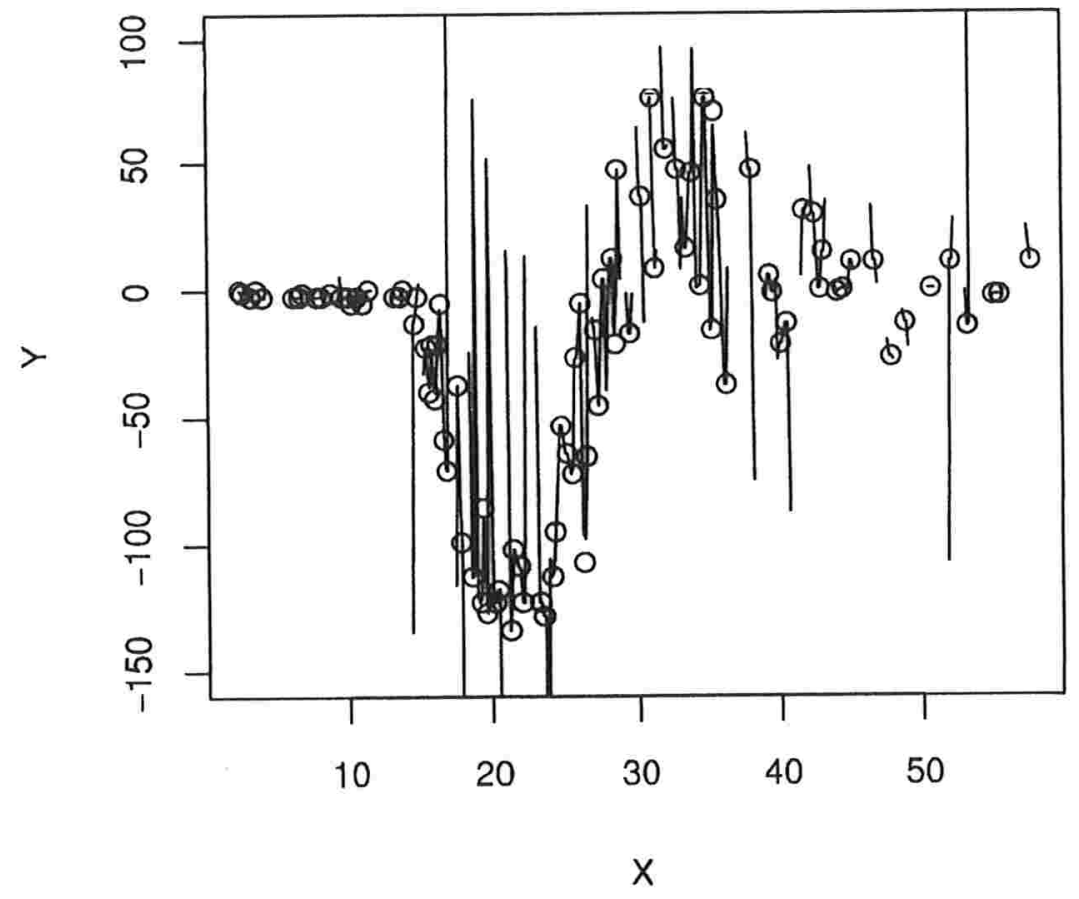

Figura 2.5: Curva ajustada pelo método de regressão polinomial local utilizando $h=0,06$. 


\section{Capítulo 3}

\section{Curvas de referência e Regressão}

\section{quantílica}

\subsection{Introdução}

Neste capítulo o método de ajuste polinomial local é utilizado na construção de curvas de referência (Harris e Boyd, 1995), bastante utilizadas em problemas reais em que se deseja avaliar se as unidades amostrais seguem, ou não, um padrão de "normalidade", segundo alguma característica de interesse.

Na área médica, as curvas de referência, por refletirem o comportamento dos indivíduos saudáveis, fornecem uma espécie de guia clínico para interpretar a informação de um novo paciente. Como citado no Capítulo 1, na área de Pediatria, por exemplo, as curvas de referência de peso ou estatura são construídas em função da idade para crianças de cada sexo, e desta forma, os valores do peso e da estatura de uma nova criança podem ser avaliados em relação ao restante da população do mesmo sexo e idade. Como ilustração, a Figura 3.1 apresenta as curvas de referência para o peso e estatura de crianças do sexo masculino com idade entre 0 e 60 meses. Assim, por exemplo, uma criança com 24 meses de 
idade e 88 centímetros de estatura é classificada no percentil $50 \%$ da população de crianças do sexo masculino com idade entre 0 e 60 meses.

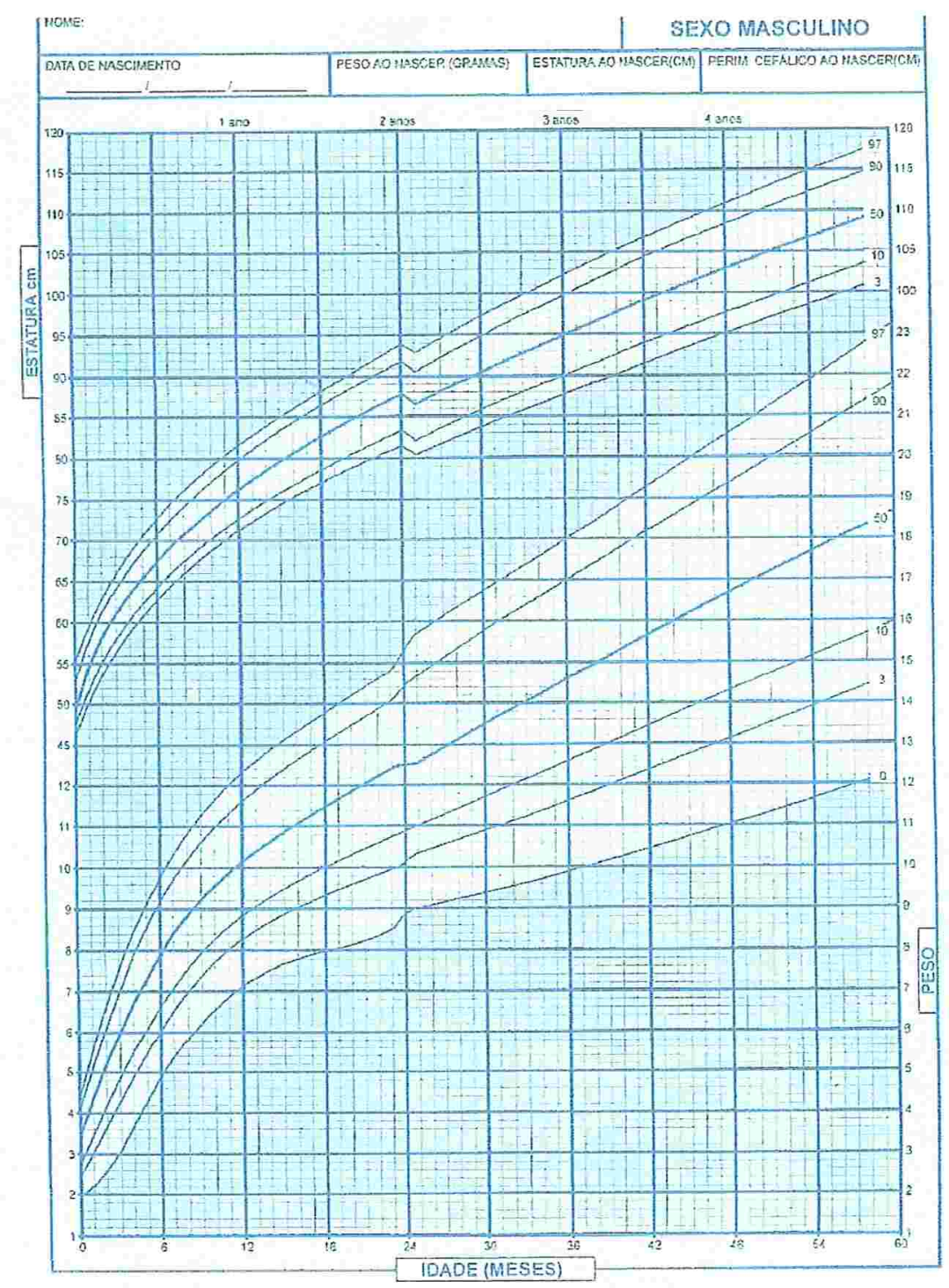

Figura 3.1: Curvas de referência do peso e estatura de crianças do sexo masculino com idade entre 0 e 60 meses. 
A construção das curvas de referência envolve a estimação dos quantis populacionais da distribuição da variável resposta $Y$, em diferentes valores da variável preditora $X$.

Formalmente, uma curva de referência de ordem $\alpha$, denotada por $\xi_{\alpha}(x)$, é dada pelo quantil populacional de ordem $\alpha$ de $Y$ para cada valor $x$ de $X$. Um Intervalo Preditivo de ordem $\gamma .100 \%, \operatorname{com} \gamma=(1-\alpha)$, é definido por:

$$
\left[\xi_{\alpha / 2}(x) ; \xi_{1-\alpha / 2}(x)\right] \text {, para } 0<\alpha<1 \text {. }
$$

Existem várias técnicas de construção de curvas de referência (ver, por exemplo, Harris e Boyd (1995) ou Sañudo (2000)). Neste trabalho nos restringiremos à apresentação de métodos nos quais regressões quantílicas (Koenker e Bassett, 1978) são ajustadas localmente.

Três métodos não paramétricos de construção de curvas de referência são apresentados nas Seções 3.2.1, 3.3.1 e 3.3.2, todos apropriados a estudos do tipo transversal. O primeiro utiliza a técnica de regressão quantílica linear local, sendo que em cada ajuste local são estimados os parâmetros de uma regressão quantílica linear. O segundo método consiste em uma versão robusta do primeiro, e incorpora no ajuste, o procedimento de atribuição de pesos proposto em Einbeck et al. (2004), o que torna a curva obtida resistente a valores discrepantes da variável preditora $X$ (soft robustification). O terceiro e último método propõe um procedimento para a deteç̧ão e posterior eliminação de valores discrepantes de $X$ (hard robustification) antes do ajuste local.

\subsection{Regressão quantílica}

Os métodos clássicos de regressão linear possibilitam a estimação da esperança condicional de $Y$ a cada valor $X=x$; a regressão quantílica, introduzida por Koenker e Bassett (1978), estima as funções quantílicas condicionais. 
Um dos atrativos da regressão quantílica está no fato de ser possível caracterizar toda a distribuição condicional da variável resposta, dadas as variáveis preditoras, fornecendo assim, uma visão mais completa da relação entre essas variáveis. Além disto, a regressão quantílica é uma técnica robusta a valores discrepantes da variável resposta $Y$.

A regressão quantílica tem sido aplicada em diversas áreas do conhecimento. Como ilustração, citamos a seguir, alguns trabalhos nos quais essa técnica foi aplicada, como por exemplo, em Economia, onde estudos foram realizados com o objetivo de analisar a relação entre o desenvolvimento financeiro e o crescimento econômico de países (Fitzenberg et al., 2002). Além deste exemplo, destaca-se também na área econômica, a utilização da regressão quantílica no estudo da distribuição dos salários de trabalhadores em função do nível de escolaridade (Martins e Pereira, 2004).

Estudos na área de Educação fazem uso da regressão quantílica modelando a distribuição do desempenho de estudantes de escolas públicas em função de algumas características como a renda dos pais, o tamanho da sala de aula e a qualificação do professor (Buchinsky, 1998).

$\mathrm{Na}$ área de Ecologia e Biologia, a regressão quantílica foi empregada para estimar os efeitos dos fatores que afetam o crescimento, a sobrevivência e a reprodução de um organismo (Cade et al., 1999); assim como também para avaliar a associação entre o tamanho da presa e do predador (Scharf et al., 1998); e ainda na investigação das mudanças na vegetação com o uso de conservantes agrícolas (Allen et al., 2001).

A regressão quantílica foi utilizada na área Médica, no estudo da associação do peso, da altura e do índice de massa corporal de indivíduos com a sua idade, como apresentado em Royston (1991), Cole et al. (1998), Royston e Wright (1998) e Heagerty e Pepe (1999) entre outros. Os leitores interessados em mais referências de aplicações da regressão quantílica podem consultar Koenker e Hallock (2001).

A função quantílica condicional de ordem $\alpha, \xi_{\alpha}(x)$, é obtida minimizando a 
expressão:

$$
\mathrm{E}\left\{1_{\alpha}\left(Y-\xi_{\alpha}(x)\right) \mid X=x\right\}, \text { para } 0<\alpha<1,
$$

com respeito a $\xi_{\alpha}(x)$, em que $1_{\alpha}(t)$ é a função de perda dada por:

$$
1_{\alpha}(t)=|t|+(2 \alpha-1) t, \text { para } 0<\alpha<1
$$

Notamos que a função de perda em (3.2) se reduz a $1_{\alpha}(t)=|t|$, quando $\alpha=0,5$, que corresponde à função de perda do método robusto de estimação $\mathrm{L}_{1}$ (Tavares, 1998).

Supondo que os dados são modelados por (2.1), a função quantílica condicional de ordem $\alpha$ no ponto $X=x$, pode ser escrita como:

$$
\xi_{\alpha}(x)=m(x)+\sigma(x) \mathrm{G}_{0}^{-1}(\alpha)
$$

em que $m(x)$ é a função de regressão, $\sigma^{2}(x)=\operatorname{Var}(Y \mid X=x)$ e $\mathrm{G}_{0}^{-1}(\alpha)$ é o quantil de ordem $\alpha$ da distribuição de $\varepsilon$. No caso particular onde $\sigma(x)=\sigma$, para todo $x$, as funções quantílicas, ou simplesmente, as curvas quantílicas ajustadas são paralelas. Na situação em que as curvas não são paralelas, sugerindo a presença de heterocedasticidade, cuidados adicionais devem ser tomados na análise estatística, como por exemplo, a transformação dos dados. Uma vasta revisão sobre os diversos tipos de transformações pode ser encontrada em Carroll e Ruppert (1988).

Quando a função de regressão $m(x)$ é especificada, como por exemplo, uma reta, e assumindo que $\sigma^{2}(x)=1$, para todo $x$, a função quantílica condicional tem a forma:

$$
\xi_{\alpha}(x)=\beta_{0}+\beta_{1} x+\mathrm{G}_{0}^{-1}(\alpha)
$$

em que $\beta_{0}$ e $\beta_{1}$ são parâmetros a serem estimados e $\mathrm{G}_{0}^{-1}(\alpha)$ é definido como em (3.3).

O processo de minimização da expressão (3.1) considerando a função de perda como em (3.2) é feito, em geral, por alguma variedade do método de programação linear simplex. Os leitores interessados neste assunto podem consultar Sultan (1993). 
Como neste trabalho o interesse principal está nos métodos de ajuste local, que utilizam a regressão quantílica quando a forma de $m(x)$ na expressão (3.3) não está específicada, não são discutidas as propriedades assintóticas dos estimadores da função quantílica paramétrica, assunto detalhadamente descrito em Koenker e Bassett (1978).

\subsubsection{Regressão quantílica local}

Uma maneira alternativa de ajustar $\xi_{\alpha}(x)$ é apresentada nesta seção, utilizando a idéia do ajuste local da função de regressão $m(x)$ apresentado no Capítulo 2. Neste caso, $\xi_{\alpha}(x)$ é ajustada localmente na vizinhança de cada ponto $x=x_{0}$ fixado a priori, minimizando a expressão:

$$
\sum_{i=1}^{n} 1_{\alpha}\left\{Y_{i}-\sum_{j=0}^{p} \beta_{j}\left(X_{i}-x_{0}\right)^{j}\right\} K\left(\frac{X_{i}-x_{0}}{h(\alpha)}\right),
$$

onde $1_{\alpha}(t)$ é definida como em $(3.2), \beta_{j}, j=0, \ldots, p$, são parâmetros a serem estimados em cada ajuste local, $p$ é o grau dos polinômios ajustados localmente, $h(\alpha)$ é o tamanho da vizinhança, que depende do quantil $\alpha$ fixado e $K($.) é a função kernel. Assim, a idéia é a mesma apresentada no Capítulo 2, com a função de perda quadrática sendo substituída pela função de perda dada em (3.2). O parâmetro de suavização $h(\alpha)$ utilizado nos ajuste de $\xi_{\alpha}($.$) , dependerá somente de \alpha$ e não do ponto alvo $x_{0}$.

No caso particular onde o ajuste linear local é adotado $(p=1)$, a expressão (3.4) se reduz a:

$$
\sum_{i=1}^{n} 1_{\alpha}\left\{Y_{i}-\beta_{0}-\beta_{1}\left(X_{i}-x_{0}\right)\right\} K\left(\frac{X_{i}-x_{0}}{h(\alpha)}\right)
$$

onde $1_{\alpha}(t)$ é definida como em $(3.2), h(\alpha)$ e $K($.$) definidos como em (3.4), \beta_{0}$ e $\beta_{1}$ são parâmetros a serem estimados em cada ajuste linear local.

Segundo Fan e Gijbels (1996), supondo $h \rightarrow 0$ e $n h \rightarrow \infty$, a variância assintótica 
de $\hat{\xi}_{\alpha}(x)$, é:

$$
\frac{\int K^{2}(u) \mathrm{d} u}{f(x) n h(\alpha)} \frac{\alpha(1-\epsilon)}{\left[g\left(\xi_{\alpha}(x) \mid x\right)\right]^{2}}+o_{p}\left(\frac{1}{n h(\alpha)}\right), \text { para } 0<\alpha<1
$$

onde $K($.$) e h(\alpha)$ são definidos como em (3.4), $f(x)$ é a densidade de $X$ no ponto $x$ e $g(. \mid x)$ é a densidade condicional de $Y$ dado $X=x$.

O valor assintoticamente ótimo para o parâmetro de suavização $h(\alpha)$ utilizado no ajuste da função quantílica de ordem $\alpha$ é obtido da expressão para o $h$ constante apresentada em (2.15), substituindo $\sigma^{2}(x)$ e $m^{(p+1)}(x)$ por $\alpha(1-\alpha)\left[g\left(\xi_{\alpha}(x) \mid x\right)\right]^{-2}$ e $\xi_{\alpha}^{(p+1)}(x)$, respectivamente, resultando em:

$$
\check{h}_{\mathrm{opt}}(\alpha)=\mathrm{C}_{j, p}(K)\left[\frac{\int \alpha(1-\alpha)\left[g\left(\xi_{\alpha}(x) \mid x\right)\right]^{-2} w(x) / f(x) \mathrm{d} x}{\int\left\{\xi_{\alpha}^{(p+1)}(x)\right\}^{2} w(x) \mathrm{d} x}\right]^{1 /(2 p+3)} n^{-1 /(2 p+3)},
$$

onde $\mathrm{C}_{j, p}(K)$ é definido como em (2.13), $g(. \mid x)$ e $f($.$) são definidos como em (3.5) e w(x)$ é uma função de peso definida a priori . Note que, se os dados são modelados por (2.1) com erros homocedásticos, então $\mathrm{g}\left(\xi_{\alpha}(x) \mid x\right)=\mathrm{g}_{1}\left(\mathrm{G}_{1}^{-1}(\alpha)\right)$, onde $\mathrm{G}_{1}($.$) e \mathrm{g}_{1}($.$) são, respec-$ tivamente, a função distribuição acumulada e a função densidade de $\sigma \varepsilon_{i}, i=1, \ldots, n$. Desta forma, quando $\alpha=0,5$ e $\mathrm{g}_{1}\left(\right.$.) é simétrica ao redor do zero, tem-se que $\mathrm{G}_{1}^{-1}(\alpha)=0$. Neste caso, o mesmo procedimento prático utilizado na obtenção do valor aproximado para o $h$ assintoticamente ótimo, $h_{\text {aprox }}$, definido em (2.17), pode ser aplicado para regressão quantílica, resultando na expressão:

$$
\check{h}_{\text {aprox }}(\alpha)=\mathrm{C}_{j, p}(K)\left[\frac{\alpha(1-\alpha)\left[\check{\mathrm{g}}_{1}\left(\check{\mathrm{G}}_{1}^{-1}(\alpha)\right)\right]^{-2} \int w_{0}(x) \mathrm{d} x}{\sum_{i=1}^{n}\left\{\check{\xi}_{\alpha}^{(p+1)}\left(X_{i}\right)\right\}^{2} w_{0}\left(X_{i}\right)}\right]^{1 /(2 p+3)},
$$

usando $w(x)=w_{0}(x) f(x)$, para uma função de peso específica $w_{0}($.$) . Aqui, \check{\xi}_{\alpha}(x)=$ $\check{\alpha}_{0}+\ldots+\check{\alpha}_{p+3} x^{p+3}$ é obtida do ajuste global de um polinômio de grau $(p+3)$. A função densidade $\check{g}_{1}($.$) pode ser estimada de forma não paramétrica a partir dos resíduos do ajuste$ polinomial global e $\check{\mathrm{G}}_{1}^{-1}(\alpha)$ é o $\alpha$-ésimo quantil amostral dos resíduos. 
Tomando a função de peso $w_{0}(x)=I_{[a, b]}(x)$, onde $[a, b]$ é o intervalo de interesse na estimação de $\xi_{\alpha}(x)$ e substituindo em (3.6), tem-se uma outra expressão para o parâmetro de suavização:

$$
\breve{h}_{\text {aprox }}(\alpha)=\mathrm{C}_{j, p}(K)\left[\frac{\alpha(1-\alpha)\left[\check{\mathrm{g}}_{1}\left\{\check{\mathrm{G}}_{1}^{-1}(\alpha)\right\}\right]^{-2}(b-a)}{\sum_{i=1}^{n}\left\{\check{\xi}_{\alpha}^{(p+1)}\left(X_{i}\right)\right\}^{2} I_{[a, b]}\left(X_{i}\right)}\right]^{1 /(2 p+3)} .
$$

Yu e Jones (1998) apresentaram uma forma simplificada que relaciona o parâmetro de suavização utilizado no ajuste da função quantílica de ordem $\alpha, \xi_{\alpha}($.$) , com o h$ ótimo utilizado no ajuste da função de regressāo $m(x)$ dado em (2.15). Supondo que a distribuiçāo condicional de $Y$ dado $X$ é Normal com média $\mu_{x}$ e variância $\sigma_{x}^{2}$, os autores obtiveram a seguinte expressão para o cálculo do parâmetro de suavização:

$$
\check{h}(\alpha)=h_{\mathrm{opt}}\left[\frac{\alpha(1-\alpha)}{\phi\left(\Phi^{-1}(\alpha)\right)^{2}}\right]^{1 / 5},
$$

onde $h_{\mathrm{opt}}$ é definido em (2.15), $\phi$ e $\Phi$ são respectivamente a função densidade e a função distribuição da Normal padrão.

\subsection{Regressão quantílica local resistente a valores dis- crepantes da variável preditora}

O método de ajuste da função quantílica apresentado na seção anterior é robusto a valores discrepantes na variável $Y$ mas não na variável $X$. Nesta seção, propomos a utilização de dois procedimentos mais resistente a valores discrepantes na variável preditora para a estimação da função quantílica: "robustificação" fraca e "robustificação" forte. 


\subsection{1 "Robustificação" fraca}

Este procedimento de ajuste foi inspirado em Einbeck et al. (2004). Nesse trabalho, a função densidade de $X, f(x)$, é incorporada à ponderação dos dados no processo de a.juste local da função de regressão $m(x)$, de forma que pontos nos quais o planejamento é esparso recebam menor peso. No ajuste local da função de regressão $m(x)$, tendo $x_{0}$ como ponto alvo, é minimizada a expressão:

$$
\sum_{i=1}^{n} 1\left\{Y_{i}-\sum_{j=0}^{p} \beta_{j}\left(X_{i}-x_{0}\right)^{j}\right\} \zeta\left(X_{i}\right) K\left(\frac{X_{i}-x_{0}}{h}\right),
$$

$\operatorname{coml}(t)=t^{2}, \beta_{j}, j=0, \ldots, p$, parâmetros a serem estimados, $\zeta($.$) qualquer função monó-$ tona crescente de $f($.$) e K($.$) a função Kernel.$

Um possível estimador para a função densidade de $X$ no ponto $x_{0}$ é dado por:

$$
\hat{f}\left(x_{0}\right)=\frac{1}{n s_{n}} \sum_{i=1}^{n} K\left(\frac{X_{i}-x_{0}}{s_{n}}\right),
$$

em que $s_{n}$ é o tamanho da vizinhança, que por sugestão de Silverman (1986) é dado por $s_{n}=0,9 A n^{-1 / 5}$, onde $A$ é:

$$
A=\min \left(\mathrm{dp}, \frac{\mathrm{IIQ}}{1,34}\right)
$$

em que dp e IIQ são respectivamente o desvio-padrão e o intervalo interquartil amostral de $X$.

Estimadores não paramétricos da funçaõ densidade de $X$ podem também ser considerados, conforme apresentam Fan e Gijbels (1996).

O procedimento de "robustificação" descrito acima pode ser adotado no ajuste da função quantílica $\xi_{\alpha}($.$) . A expressão a ser minimizada é, então:$

$$
\sum_{i=1}^{n} 1_{\alpha}\left\{Y_{i}-\xi_{\alpha}\left(X_{i}-x_{0}\right)\right\} \zeta\left(X_{i}\right) K\left(\frac{X_{i}-x_{0}}{h(\alpha)}\right),
$$


com respeito a $\xi_{\alpha}($.$) , para 0<\alpha<1$, em que $l_{\alpha}(t)$ é a função de perda definida em (3.2) e $\zeta($.$) e \hbar($.$) definidos como em (3.8).$

É importante notar que o papel de $\zeta($.$) em (3.10) é reduzir o efeito dos valores$ discrepantes de $X$ na estimação de $\xi_{\alpha}($.$) . Essa redução pode ser mais efetiva se considerar-$ $\operatorname{mos} \zeta()=.f^{k}()$, com $k>1$. Conforme mostrado em Einbeck et al. (2004), quanto maior for o valor de $k$, mais robusto se torna o procedimento de estimação. Contudo, esse expoente $k$ não deve aumentar arbitrariamente, pois os estimadores tornam-se instáveis. Na Seção 3.4 ilustramos o efeito da introdução da função densidade de $X$ nos pesos atribuídos nos ajustes locais.

\subsection{2 "Robustificação" forte}

No processo de robustificação do ajuste da função quantílica descrito na seção anterior, o efeito dos valores discrepantes na variável $X$ é minimizado, mas não é totalmente eliminado.

O método de ajuste da função quantílica descrito nesta seção foi também inspirado em Einbeck et al. (2004), que, na tentativa de reduzir os efeitos dos valores discrepantes de $X$ no processo de ajuste da função de regressão $m(x)$, sugere um procedimento para a detecção desses valores que são então eliminados. São considerados discrepantes os valores de $X$ com densidade estimada abaixo de certo limiar (valor de corte).

Para determinação desse valor de corte, os autores sugerem que a função densidade de $X$ seja estimada pela função densidade Normal com média igual à mediana amostral de $X$, e desvio-padrão $A$ definido como na expressão (3.9).

Considerando $d$ como a proporção esperada de valores discrepantes na variável $X$, que em geral é de $1 \%$ a $5 \%$, o valor de corte utilizado no critério de eliminação dos 
pontos é dado por:

$$
\delta=\phi_{\mu, A^{2}}\left(x_{d / 2}\right)=\phi_{\mu, A^{2}}\left(\mu+A \cdot z_{d / 2}\right)=\frac{1}{A} \phi\left(z_{d / 2}\right) .
$$

onde $\phi$ é a função densidade Normal com média igual à mediana amostral de $X$ e desviopadrão $A$, e $x_{d / 2}$ e $z_{d / 2}$ são os quantis de ordem $d / 2$ da distribuição estimada de $X$ e da distribuição Normal padrão, respectivamente.

A curva de referência ajustada de ordem $\alpha, \hat{\xi}_{\alpha}($.$) , é obtida minimizando a ex-$ pressão:

$$
\sum_{i=1}^{n} 1_{\alpha}\left\{Y_{i}-\xi_{\alpha}\left(X_{i}-x_{0}\right)\right\} \zeta\left(X_{i}\right) \mathrm{I}\left\{f\left(X_{i}\right)>\delta\right\} K\left(\frac{X_{i}-x_{0}}{h(\alpha)}\right),
$$

com respeito a $\xi_{\alpha}($.$) , para 0<\alpha<1$, em que $1_{\alpha}(t)$ é definida como em (3.2), $\zeta($.$) ,$ $K($.$) definidos como em (3.8) e h(\alpha)$ definido como em (3.4).

\subsection{Efeito da "robustificação" no ajuste da função quan- tílica local}

Nesta seção vamos ilustrar o comportamento dos procedimentos apresentados nas Seções 3.2.1, 3.3.1 e 3.3.2 no ajuste das funções quantílicas de ordem $50 \%, \xi_{50 \%}(x)$.

Com tal finalidade, foi gerada uma amostra de 50 observações a partir do modelo $y_{i}=\left(x_{i}-3\right)^{2}+\varepsilon_{i}$. Os valores $x_{i}$ foram obtidos a partir da distribuição Uniforme no intervalo $[0,6]$, e os erros $\varepsilon_{i}$ foram gerados a partir de uma distribuição Normal com média 0 e desvio-padrão $0,6, i=1, \ldots, 50$. Para a visualização do efeito de "robustificação" dos métodos apresentados, foram acrescentados a amostra sete pontos com valores discrepantes na variável $X:(7 ; 6,2),(7,7 ; 4),(8,2 ; 3),(7,9 ; 1,8),(8,5 ; 2,9),(8,9 ; 2)$ e $(8,5 ; 0,5)$. Esses pontos foram introduzidos um a um ao banco de dados, para posterior ajuste das curvas e estão representados com cores diferentes nas Figuras 3.2 e 3.3. Em todos os ajustes foram utilizados polinômios de primeiro grau $(p=1)$, tendo sido fixado em todos 
eles $h(50 \%)=0,3$, obtido por inspeção do diagrama de dispersão de $Y$ e $X$, e escolhida a função Kernel Normal.

A Figura 3.2 ilustra o comportamento dos ajustes linear local não robusto e do robusto fraco, considerando neste último $\hat{\zeta}(x)=\hat{f}(x)$ e $\hat{\zeta}(x)=\hat{f}^{2}(x)$. O ajuste robusto fraco é claramente mais resistente a valores discrepantes $X$ que o ajuste linear local não robusto. A utilização da $\hat{f}^{2}(x)$ no ajuste robusto apresenta um melhor efeito na "robustificação" da curva ajustada quando comparado ao ajuste utilizando $\hat{f}(x)$.

O comportamento das curvas ajustadas pelo método robusto forte considerando $\hat{\zeta}(x)=\hat{f}(x)$ e $\hat{\zeta}(x)=\hat{f}^{2}(x)$, conforme ilustra a Figura 3.3 , são bastante semelhantes até a adição do quinto valor discrepante. Com a introdução de mais valores discrepantes, as curvas começam a se diferenciar, tornando visível o comportamento mais robusto da curva utilizando $\hat{f}^{2}(x)$.

É importante observar que as curvas ajustadas pelo método robusto fraco são influenciadas já na introdução do primeiro valor discrepante (ver Figura 3.2), o que não ocorre com as curvas ajustadas pelo método robusto forte, sendo estas influenciadas apenas quando o sexto valor discrepante é introduzido, isto é, até a adição do quinto ponto, este método os identifica como discrepantes e os elimina do processo de ajuste (ver Figura 3.3). 

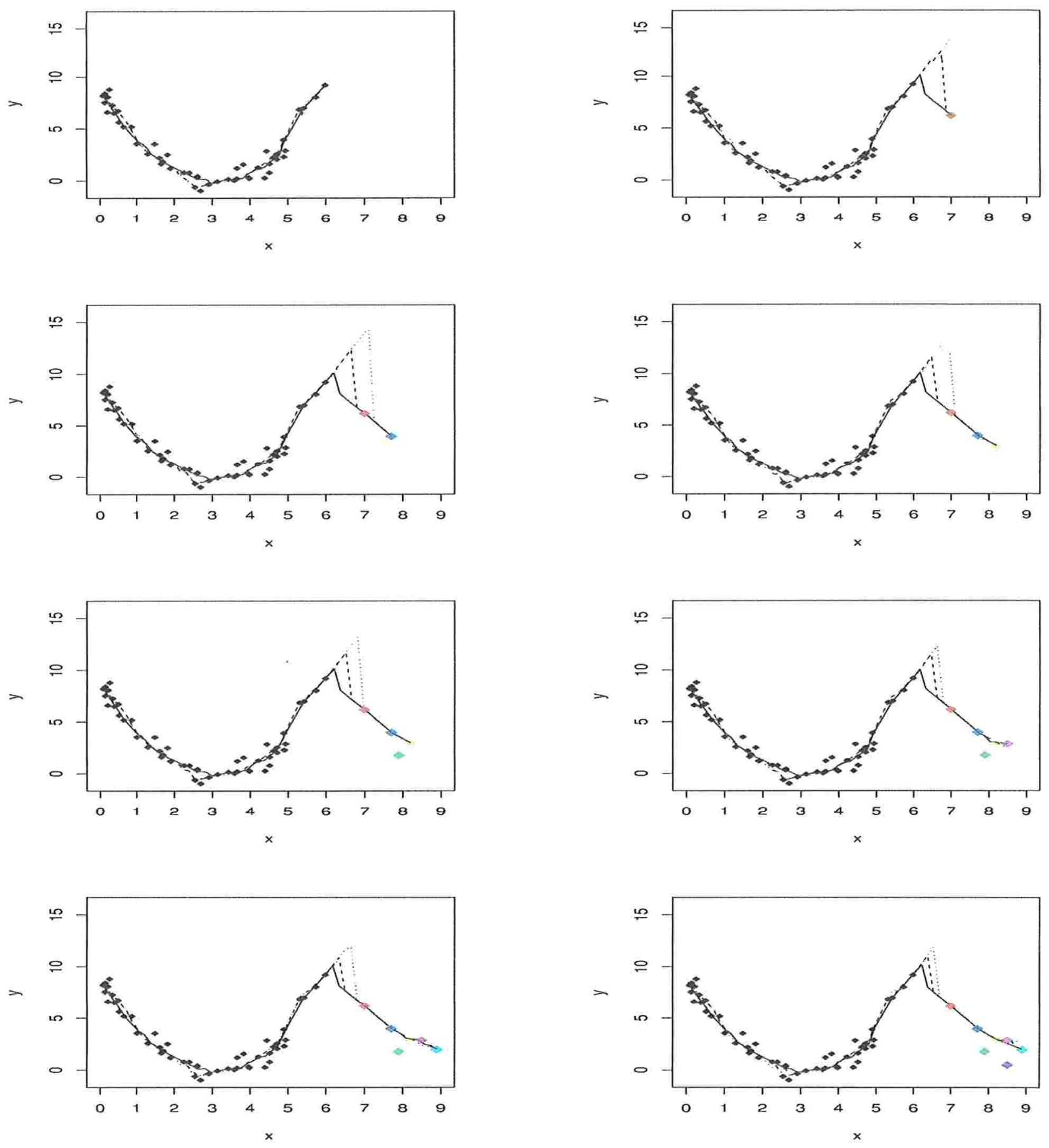

Figura 3.2: Ajuste linear local não robusto (linha sólida) e com "robustificação" fraca ponderada pela densidade de $X$ (linha tracejada) e pela segunda potência da densidade de $X$ (linha pontilhada) variando o número de pontos com valores discrepantes na variável $X$ (pontos coloridos). 

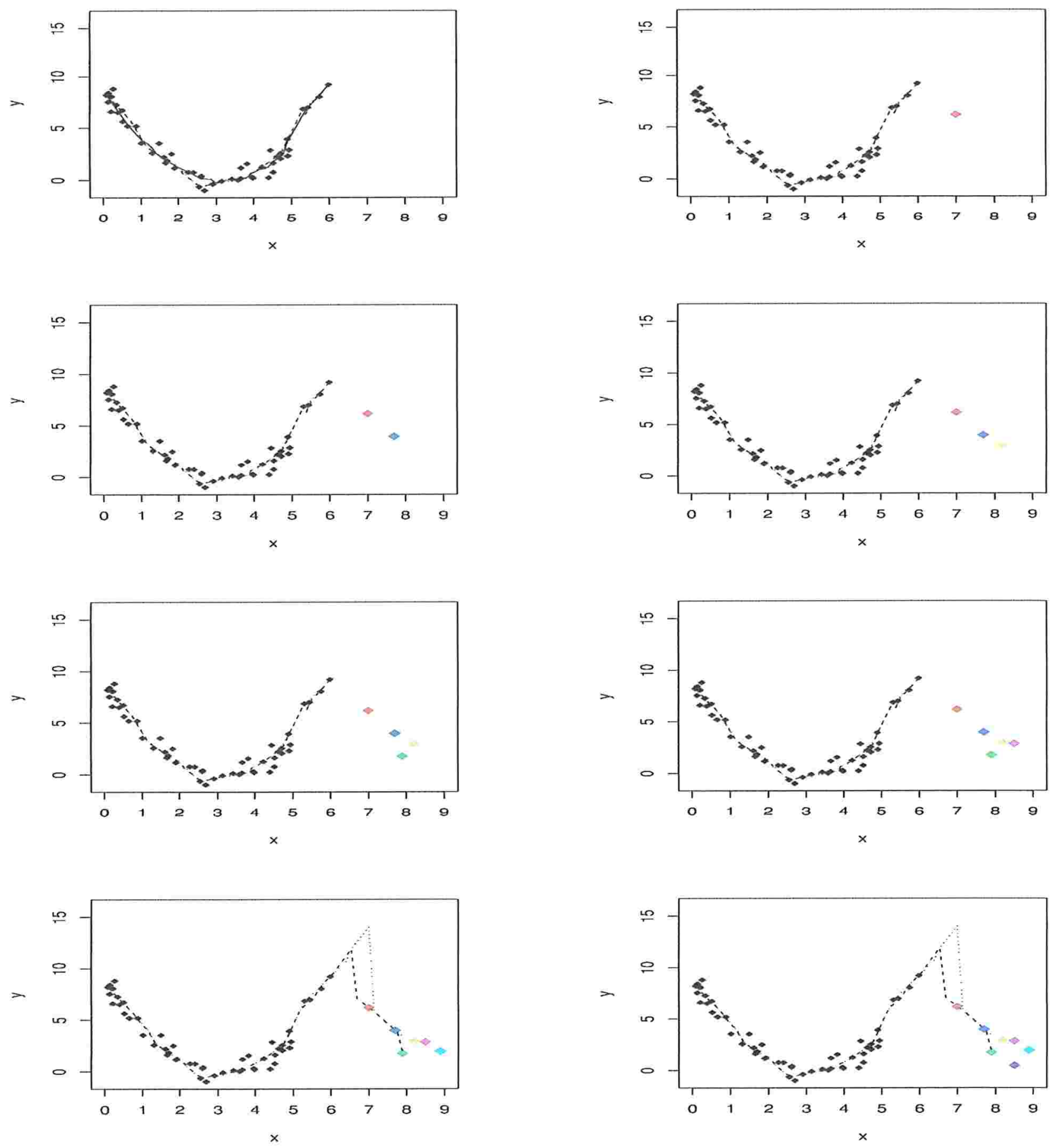

Figura 3.3: Ajuste com "robustificação" forte ponderada pela densidade de $X$ (linha tracejada) e pela segunda potência da densidade de $X$ (linha pontilhada) variando o número de pontos com valores discrepantes na variável $X$ (pontos coloridos). 


\section{Capítulo 4}

\section{Aspectos computacionais no ajuste da função quantílica local}

Neste capítulo são apresentados os procedimentos computacionais utilizados no ajuste da função quantílica local através dos métodos robustos e não robusto, descritos no Capítulo 3.

O ajuste local não robusto da função quantílica de ordem $\alpha, \xi_{\alpha}(x)$, é feito utilizando a função lprq do pacote quantreg do Software R, disponível em http: //www.r-project.org. Esta função solicita do usuário os valores da variável resposta $\mathbf{Y}$ e da variável preditora $\mathbf{X}$, o quantil desejado $(\alpha)$, o número de pontos $(b)$ da função quantílica que se deseja estimar, e por fim, o parâmetro de suavização $(h(\alpha))$, que deverá ser fixado pelo usuário através de um dos métodos descritos no Capítulo 3, ou por meio da inspeção do diagrama de dispersão.

A rotina da função lprq encontra-se na íntegra no Apêndice C e consiste na execução dos seguintes passos:

(i) Um vetor a é criado, tal que a é uma progressão aritmética de tamanho $b$ com o 
primeiro elemento igual ao menor valor de $\mathbf{X}$ e o último elemento igual ao maior valor de $\mathbf{X}$;

Os passos (ii) a (iv) abaixo são repetidos $b$ vezes, isto é, o índice $i$ varia de 1 a $b$.

(ii) Um vetor $\mathbf{Z}_{i}$ é criado, tal que $\mathbf{Z}_{i}$ é o vetor $\mathbf{X}$ subtraído do $i$-ésimo elemento do vetor $\mathbf{a}(\mathbf{a}[i])$

(iii) A função quantílica de ordem $\alpha, \xi_{\alpha}(x)$, é ajustada utilizando $\mathbf{Y}$ como variável resposta e $\mathbf{Z}_{i}$ como variável preditora;

(iv) O ponto $\left(\mathbf{a}[i] ; \hat{\xi}_{\alpha}(\mathbf{a}[i])\right)$ é colocado no diagrama de dispersão de $Y$ e $X$.

É importante notar que no passo (iii) a função quantílica ajustada é $\hat{\xi}_{\alpha}(x)=$ $\hat{\beta}_{0}+\hat{\beta}_{1} \mathbf{Z}=\hat{\beta}_{0}+\hat{\beta}_{1}(x-\mathbf{a}[i])$, onde $\hat{\beta}_{0}$ e $\hat{\beta}_{1}$ são as estimativas de $\beta_{0}$ e $\beta_{1}$. Além disso, quando $x=\mathbf{a}[i]$ tem-se que $\hat{\xi}_{\alpha}(x)=\hat{\beta}_{0}$.

Assim procedendo para todos os valores do vetor $\mathbf{a}$, temos $b$ pontos no diagrama de dispersão e a interpolação destes pontos é a função quantílica não paramétrica ajustada de ordem $\alpha$ desejada, $\hat{\xi}_{\alpha}(x)$.

Para um melhor entendimento dos passos seguidos para o ajuste da função quantílica condicional, exemplificaremos o ajuste da função quantílica de ordem 97,5\%a utilizando a amostra de 10 observações apresentada na Tabela 4.1 e representada no diagrama de dispersão na Figura 4.1. Os valores $x_{i}$ foram obtidos a partir da distribuição Normal com média 25 e desvio-padrão 3. De forma independente, foram gerados erros $\varepsilon_{i}$ segundo uma distribuição Normal padrão. As respostas $y_{i}$ foram obtidas pela relação $y_{i}=28+1,8 x_{i}+\varepsilon_{i}, i=1, \ldots, 10$. 
Tabela 4.1: Amostra gerada.

\begin{tabular}{ccc}
\hline \hline$i$ & $y_{i}$ & $x_{i}$ \\
\hline \hline 1 & 69 & 24 \\
2 & 65 & 22 \\
3 & 78 & 29 \\
4 & 82 & 28 \\
5 & 76 & 27 \\
6 & 80 & 26 \\
7 & 70 & 23 \\
8 & 72 & 25 \\
9 & 65 & 20 \\
10 & 81 & 30 \\
\hline \hline
\end{tabular}




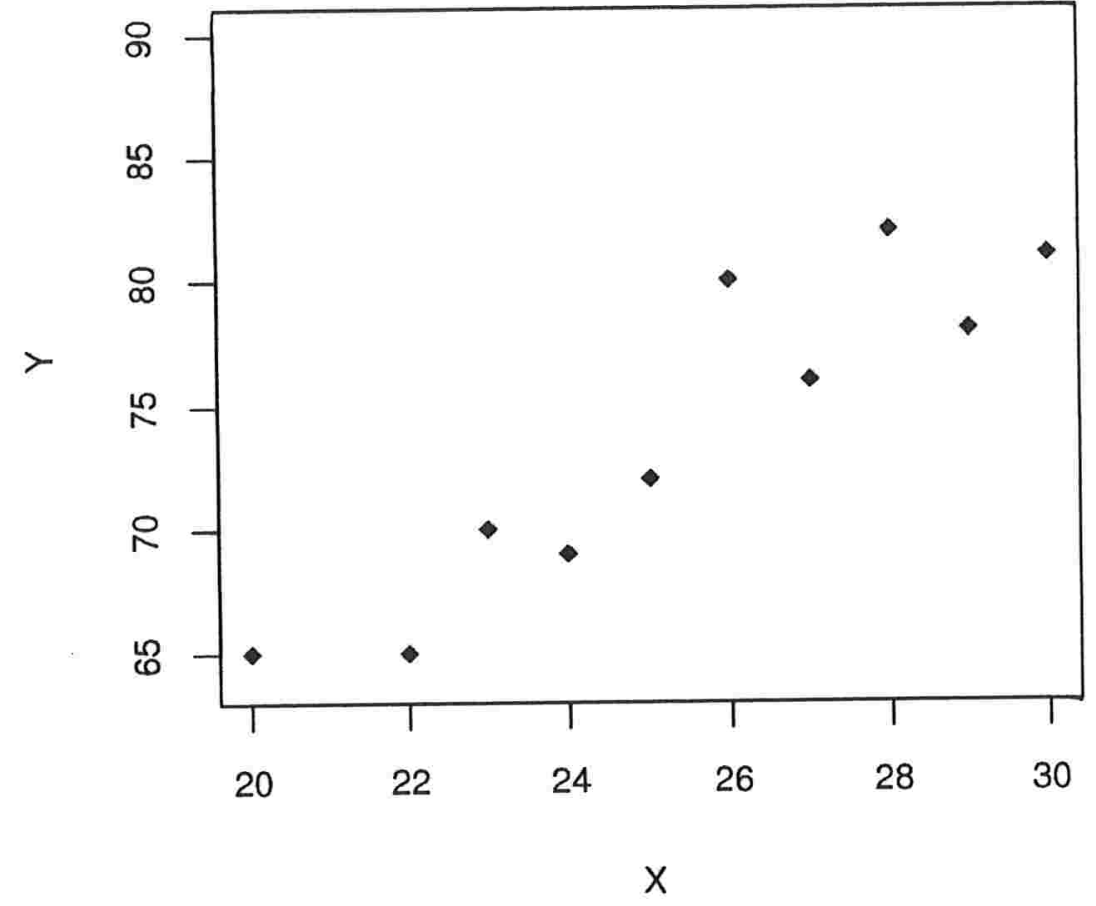

Figura 4.1: Diagrama de dispersão dos dados apresentados na Tabela 4.1.

Fixando que $\alpha=97,5 \%, b=5$ e $h(97,5 \%)=1,5$, obtido por inspeção do diagrama de dispersão na Figura 4.1, tem-se que o vetor a é:

$$
\mathbf{a}=\left(\begin{array}{c}
20 \\
22,5 \\
25 \\
27,5 \\
30
\end{array}\right) \text {. }
$$

Na determinação do primeiro ponto da função quantílica são utilizados os vetores $\mathbf{Y}$, como variável resposta, e $\mathbf{Z}_{1}$, como variável preditora, tal que $\mathbf{Z}_{1}=\mathbf{X}-20$, ou seja,

$$
\mathbf{Z}_{1}=\left(\begin{array}{llllllllll}
4 & 2 & 9 & 8 & 7 & 6 & 3 & 5 & 0 & 10
\end{array}\right)^{T},
$$

resultando em $\hat{\xi}_{97,5 \%}(20)=65$. 
O ponto $(20 ; 65)$ é colocado no diagrama de dispersão de $Y$ e $X$.

Na determinação do segundo ponto tem-se que $\mathbf{Z}_{2}=\mathbf{X}-22,5$, ou seja,

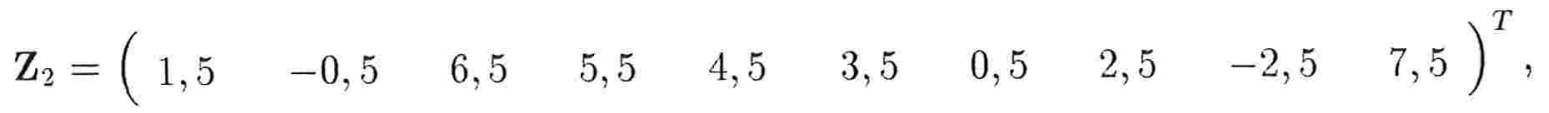

obtém-se $\hat{\xi}_{97,5 \%}(22,5)=71,3$.

Da mesma forma, o ponto $(22,5 ; 71,3)$ é colocado no diagrama de dispersão de $Y$ e $X$

A determinação dos demais pontos segue os mesmos passos. A Tabela 4.2 apresenta os pontos obtidos da função quantílica ajustada e o vetor $\mathbf{Z}_{i}$ em cada um dos $i$ passos considerados.

Tabela 4.2: Pontos $\left(\mathbf{a}[i] ; \hat{\xi}_{97,5 \%}(\mathbf{a}[i])\right)$ e os respectivos vetores $\mathbf{Z}_{i}$ no processo de ajuste da curva quantílica de ordem $97,5 \%$.

\begin{tabular}{ccccccccccccc}
\hline \hline$i$ & $\left(\mathrm{a}[i] ; \hat{\xi}_{97,5 \%}(\mathbf{a}[i])\right)$ & \multicolumn{10}{c}{ Vetor $\mathbf{Z}_{i}$} \\
\hline \hline 1 & $(20 ; 65)$ & $(4$ & 2 & 9 & 8 & 7 & 6 & 3 & 5 & 0 & $10)^{T}$ \\
2 & $(22,5 ; 71,3)$ & $(1,5$ & $-0,5$ & 6,5 & 5,5 & 4,5 & 3,5 & 0,5 & 2,5 & $-2,5$ & $7,5)^{T}$ \\
3 & $(25 ; 77,5)$ & $(-1$ & -3 & 4 & 3 & 2 & 1 & -2 & 0 & -5 & $5)^{T}$ \\
4 & $(27,5 ; 81,5)$ & $(-3,5$ & $-5,5$ & 1,5 & 0,5 & $-0,5$ & $-1,5$ & $-4,5$ & $-2,5$ & $-7,5$ & $2,5)^{T}$ \\
5 & $(30 ; 81)$ & $(-6$ & -8 & -1 & -2 & -3 & -4 & -7 & -5 & -10 & $0)^{T}$ \\
\hline \hline
\end{tabular}

A função quantílica de ordem $97,5 \%$ ajustada é obtida interpolando os pontos $\left(\mathbf{a}[i] ; \hat{\xi}_{97,5 \%}(\mathbf{a}[i])\right), i=1 \ldots, 5$, e está representada na Figura 4.2 . 


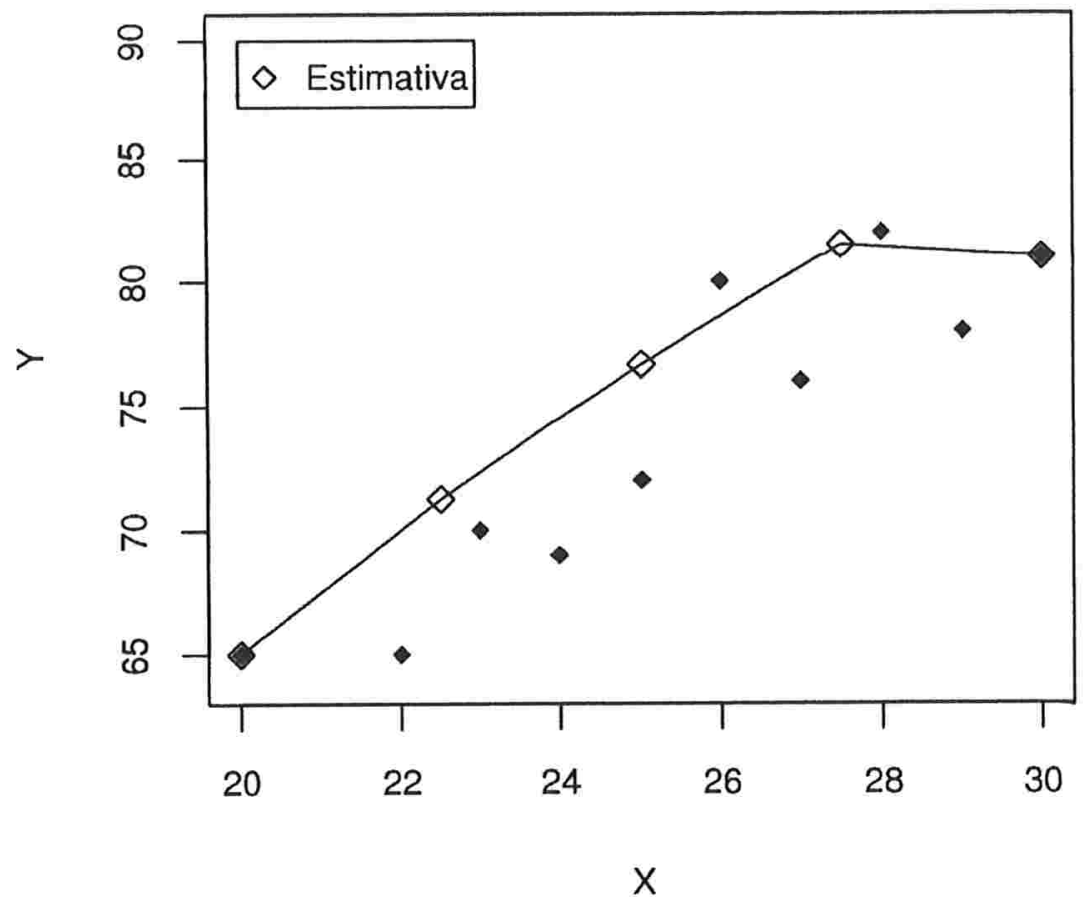

Figura 4.2: Curva de ordem 97,5\% para os dados apresentados na Tabela 4.1, ajustada pelo método local não robusto.

O ajuste da função quantílica robusta a valores discrepantes de $X$ é feito introduzindo uma alteração na função lprq do Software R: a função peso utilizada no processo de ajuste da curva é multiplicada pela função densidade estimada de $X$. Desta forma, o peso utilizado no ajuste da curva robusta incorpora a informação da densidade de $X$.

No ajuste da curva robusta utilizando a segunda potência da função densidade estimada de $X, \hat{f}^{2}(x)$, o peso utilizado é multiplicado por $\hat{f}^{2}(x)$, e assim, para as demais potências que se queira considerar.

Para efeito de ilustração, a Figura 4.3 apresenta o comportamento da curva ajustada pelo método de regressão quantílica local não robusto, bem como das curvas ajustadas pelo método robusto considerando o parâmetro de suavização $h(97,5 \%)=3,5 \mathrm{em}$ todos os ajustes (obtido por inspeção do diagrama de dispersão). É importante notar que as curvas obtidas pelos métodos robustos, indistinguíveis visualmente, apresentam 
exatamente o mesmo comportamento, e comparando-as com a curva obtida pelo método local não robusto, pode-se notar um pequeno distanciamento nas proximidades dos pontos $(25 ; 72)$ e $(30 ; 81)$.

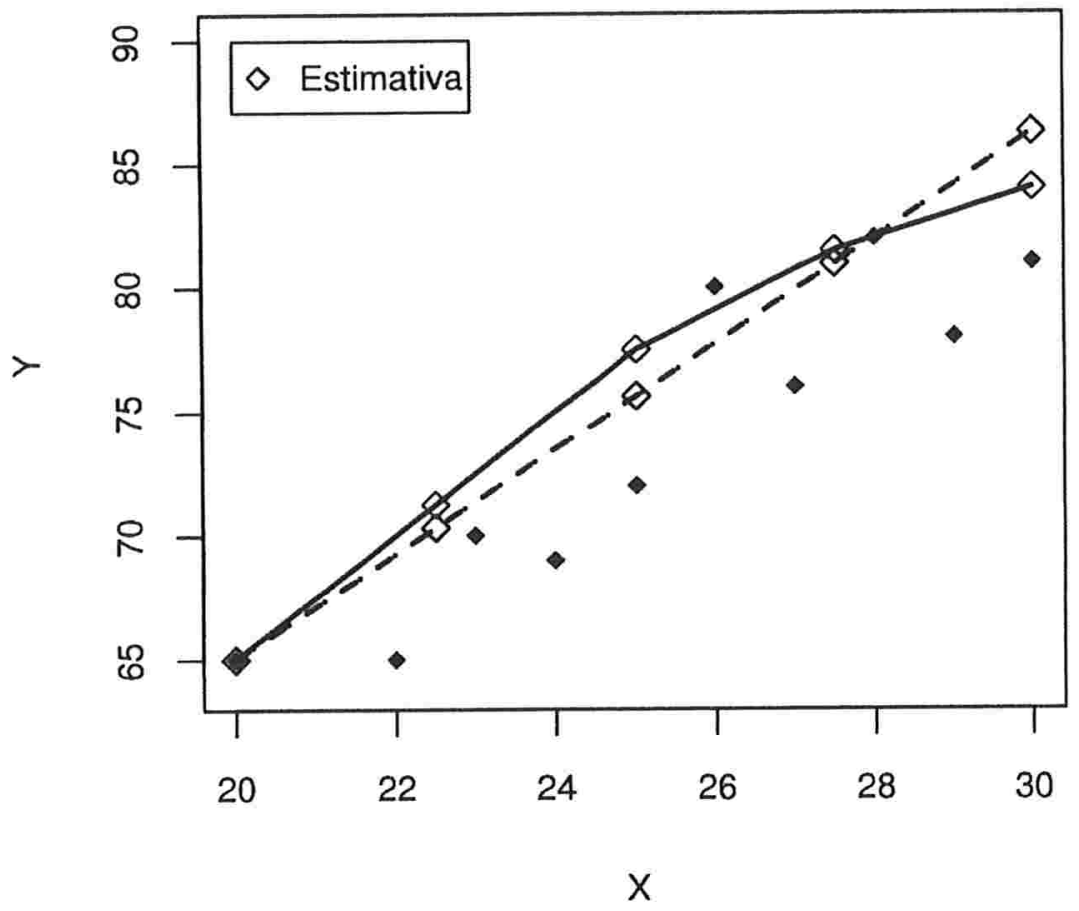

Figura 4.3: Curvas de ordem 97,5\% para os dados apresentados na Tabela 4.1.

ajustadas pelo método local não robusto (linha sólida) e com "robustificação" fraca ponderada pela densidade de $X$ (linha tracejada) e pela segunda potência da densidade de $X$ (linha pontilhada). 


\section{Capítulo 5}

\section{Aplicação}

\subsection{Apresentação do problema}

Neste capítulo é feita uma aplicação dos procedimentos de ajuste local das curvas quantílicas condicionais discutidos no Capítulo 3. O conjunto de dados utilizado foi obtido de um estudo realizado no Instituto do Coração da Faculdade de Medicina da Universidade de São Paulo (Incor-USP), com o objetivo de descrever a atividade elétrica do coração em indivíduos que passaram por uma rigorosa triagem clínica e não apresentaram nenhum sintoma ou doença relacionados ao sistema cardiovascular. Estes dados foram inicialmente analisados por André et al. (2002).

A Cardiologia médica dispõe de muitos métodos auxiliares no diagnóstico de patologias que se manifestam no sistema cardiovascular. Um deles é o eletrocardiograma de longa duração, também conhecido como Holter, no qual a atividade elétrica do coração é monitorada de forma prolongada durante as atividades rotineiras dos indivíduos. Os batimentos são registrados em uma fita $\mathrm{K} 7$ durante o período de 24 horas e depois analisados por um sistema computadorizado.

A amostra coletada nesta pesquisa é composta por 625 indivíduos de ambos os 
sexos e de diferentes faixas etárias entre aquelas que procuraram o InCor-USP para exame de rotina (check-up).

Neste trabalho a construção das curvas de referência é feita considerando apenas o grupo feminino, composto por 349 mulheres, uma vez que foi detectado o efeito da variável sexo no ritmo cardíaco, conforme resultados inferenciais apresentados em André et al. (2002).

A variável resposta considerada é a freqüência cardíaca (FC) média, medida em batimentos por minutos, calculada a partir de medidas da freqüência cardíaca durante um período de 24 horas e a variável preditora é a idade (anos). São ajustadas curvas de referência de ordem $2,5 \%, 50 \%$ e $97,5 \%$ pelos métodos descritos no Capítulo 3 , utilizando os valores para o parâmetro de suavização iguais a 8,9 nos ajustes das curvas de 2,5\% e $97,5 \%$, e o valor de 6,6 no ajuste da curva de $50 \%$, obtidos da expressão (3.7) considerando $h_{\mathrm{opt}}=6,1$.

A Figura 5.1 mostra o diagrama de dispersão da freqüência cardíaca média $(Y)$ e a idade $(X)$ juntamente com as curvas de referência ajustadas de ordem 2,5\%, $50 \%$ e $97,5 \%$ utilizando o método local não robusto descrito na Seção 3.2.1. É importante lembrar que as curvas de $2,5 \%$ e $97,5 \%$ compõem o intervalo preditivo de $95 \%$. 


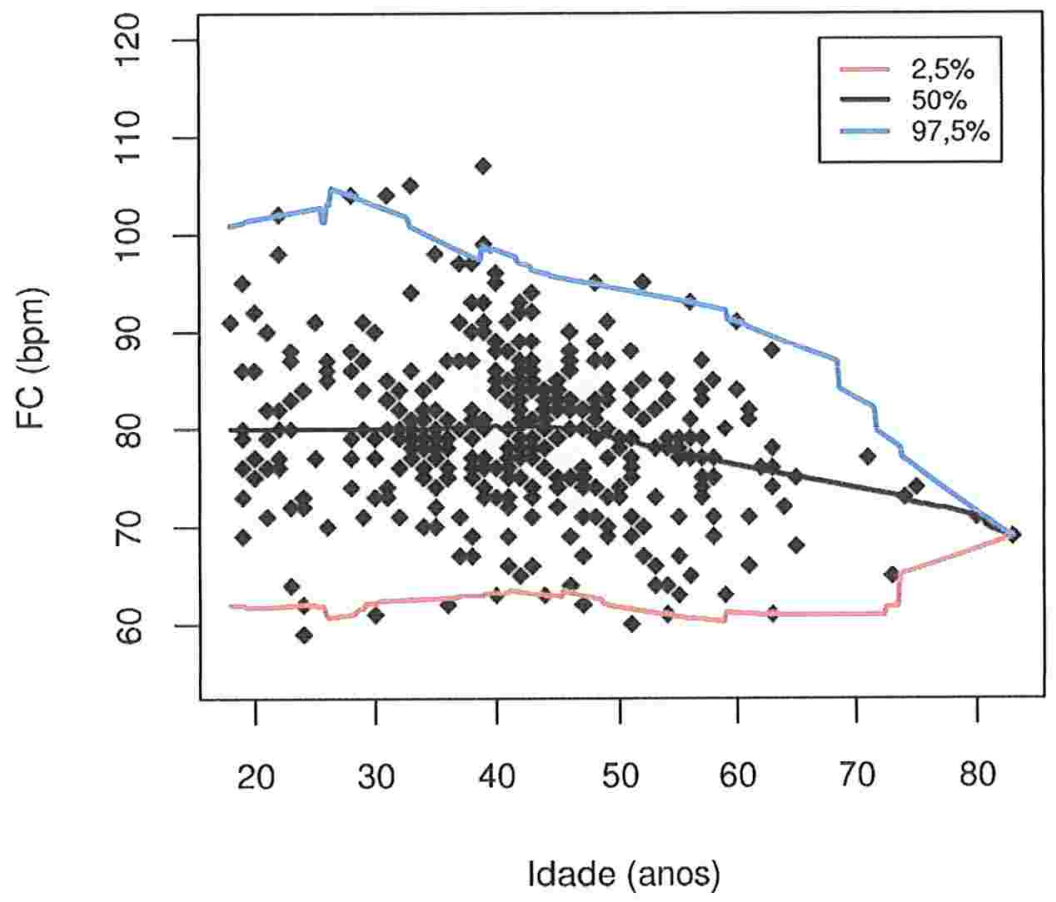

Figura 5.1: Curvas de referência de ordem $2,5 \%, 50 \%$ e $97,5 \%$ ajustadas utilizando o método local não robusto.

Note que as curvas de referência ilustradas na Figura 5.1 são bastante influenciadas pelos pontos correspondentes aos poucos indivíduos com idade acima de 65 anos. Na tentativa de reduzir essa influência, é utilizado o método de "robustificação" fraca, descrito na Seção 3.3.1.

A Figura 5.2 ilustra as curvas de referência de ordem 2,5\%, 50\% e 97,5\% ajustadas utilizando o método de "robustificação" fraca e o método local não robusto. Observamos que as curvas obtidas pelo método robusto fraco, ao contrário das ajustadas pelo método local não robusto, são menos afetadas pelos valores da idade acima de 65 anos. 


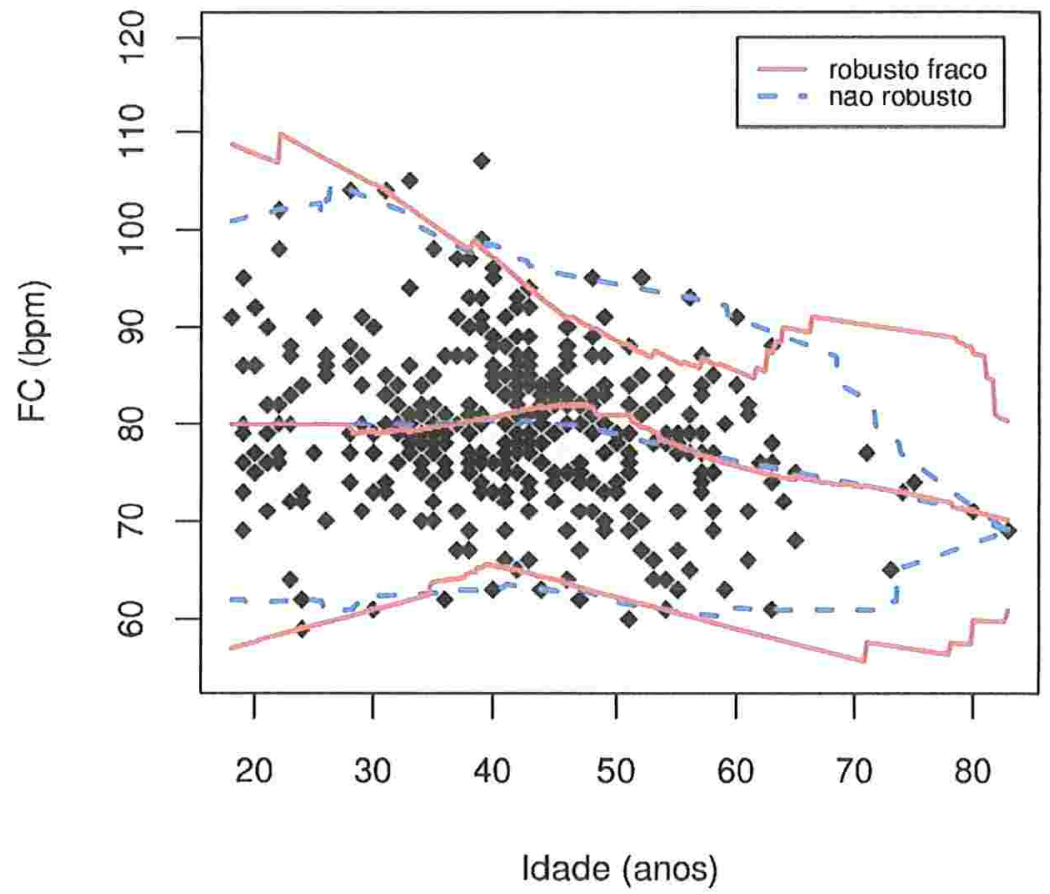

Figura 5.2: Curvas de referência de ordem 2,5\%, 50\% e 97,5\% ajustadas considerando o método de "robustificação" fraca e o método local não robusto.

O ajuste das curvas de referência utilizando o método de "robustificação" forte, descrito na Seção 3.3.2 também foi aplicado. Foram considerados como valores discrepantes de $X$ aqueles com densidade estimada abaixo de 0,05 , o que corresponde a valores de idades maiores ou iguais a 70,7 anos. Desta forma, com base nesse critério, foram retirados da amostra 6 pontos, levando à redução do tamanho da amostra em cerca de 1,7\%, que passou de 349 para 343 mulheres. Assim, o método de "robustificação" forte não foi afetado pelos valores da idade que ocorreram com baixa freqüência.

A Figura 5.3 apresenta as curvas ajustadas pelos métodos de "robustificação" forte e fraca. No intervalo de valores onde as curvas são comparáveis observa-se certa semelhança de comportamento. O método de "robustificação" forte não considerou os pontos discrepantes representados em verde na Figura 5.3. Note ainda um certo distanciamento das curvas de $97,5 \%$ obtidas pelos dois métodos para as idades entre 54 a 67 anos. 


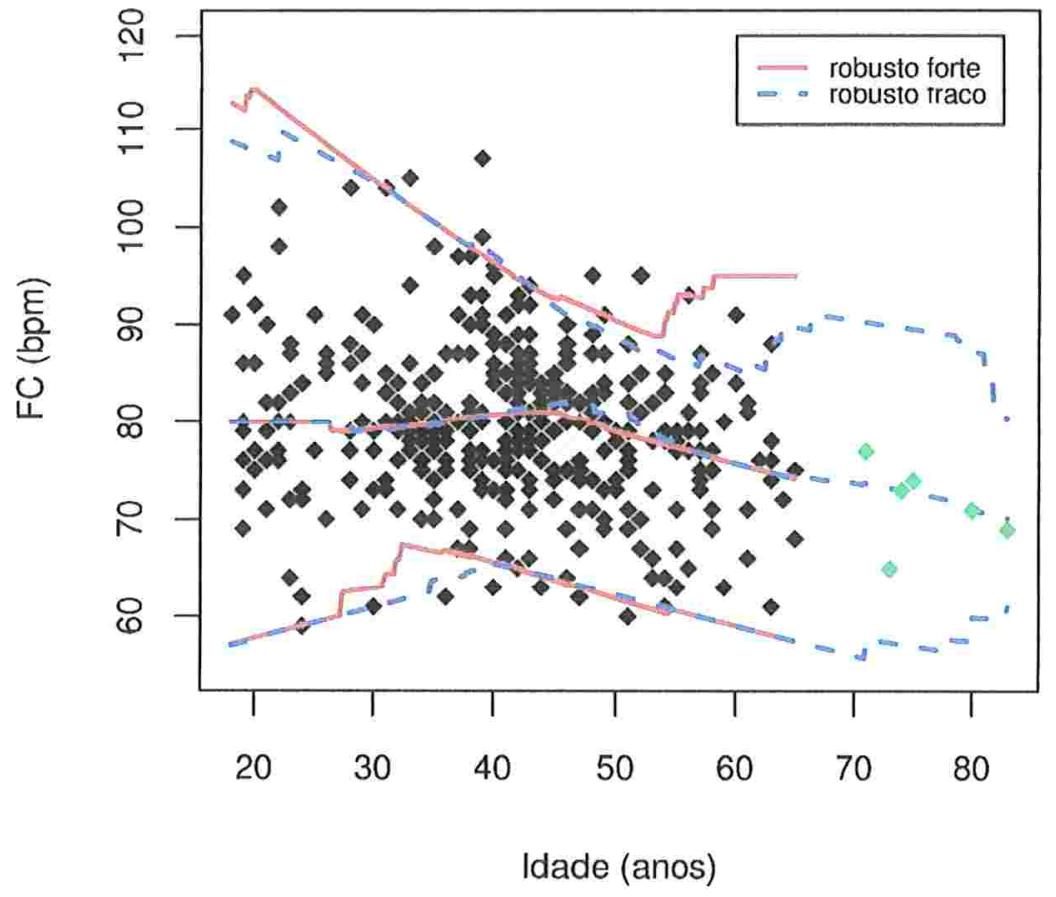

Figura 5.3: Curvas de referência de ordem 2,5\%, 50\% e 97,5\% ajustadas considerando os métodos de "robustificação" forte e fraca.

As curvas obtidas pelos métodos robustos (ver Figura 5.3) com o parâmetro de suavização dado pela expressão (3.7) são bastante rústicas, o que pode não ter interpretação na área de cardiologia. Uma maneira de resolver este problema é alterar o parâmetro de suavização buscando, através da inspeção visual, produzir curvas mais suaves. A Figura 5.4 apresenta as curvas ajustadas considerando o valor para o parâmetro de suavização igual a 15 nos ajustes das curvas de $2,5 \%$ e $97,5 \%$, e o valor de 6,6 no ajuste da curva de $50 \%$. 


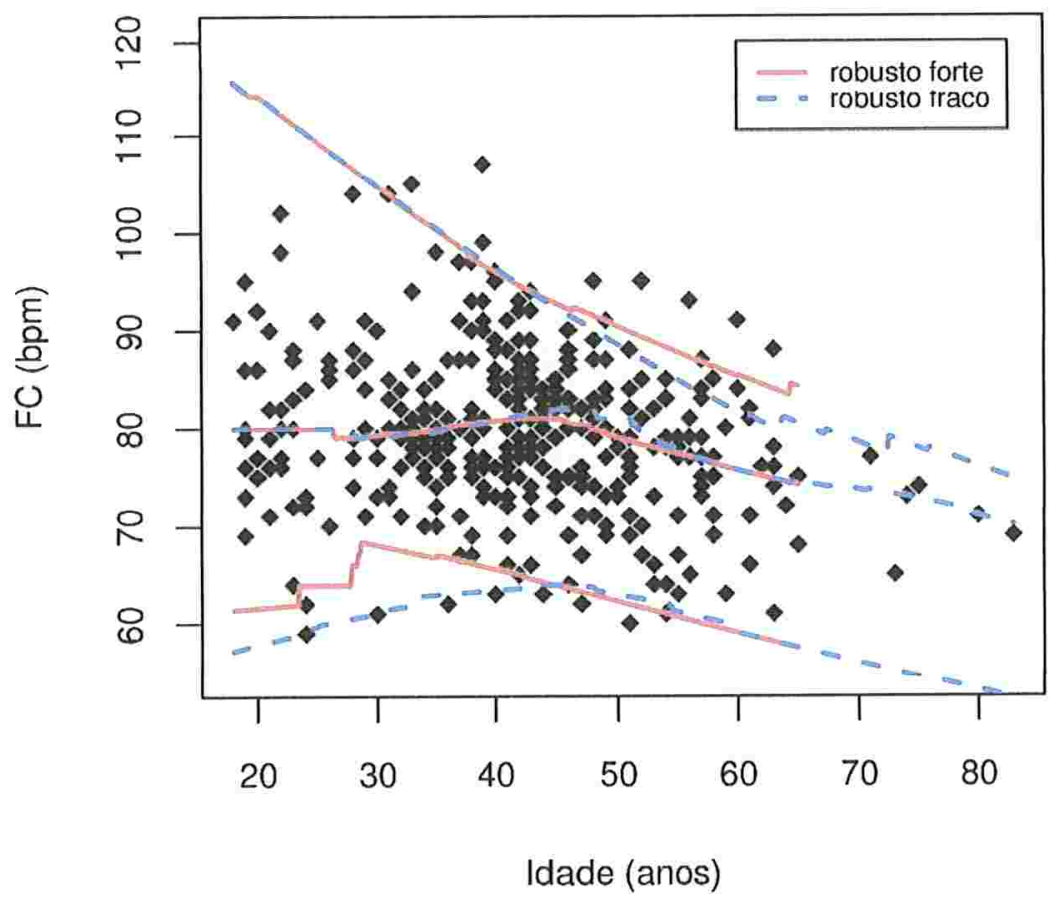

Figura 5.4: Curvas de referência de ordem 2,5\%, 50\% e 97,5\% ajustadas considerando os métodos de "robustificação" forte e fraca.

Outra maneira de se obter curvas mais suaves é ajustar localmente polinômios de primeiro grau, considerando como "observações"da variável resposta os valores ajustados pelos métodos robustos. Assim, estaríamos empregando um segundo procedimento de suavização na construção da curva, em vez de simplesmente interpolarmos os valores ajustados. Como ilustração, a Figura 5.5 apresenta as curvas de 97,5\% obtidas pelos métodos robustos quando é feita a interpolação dos dados e quando um segundo processo de suavização é adotado. 


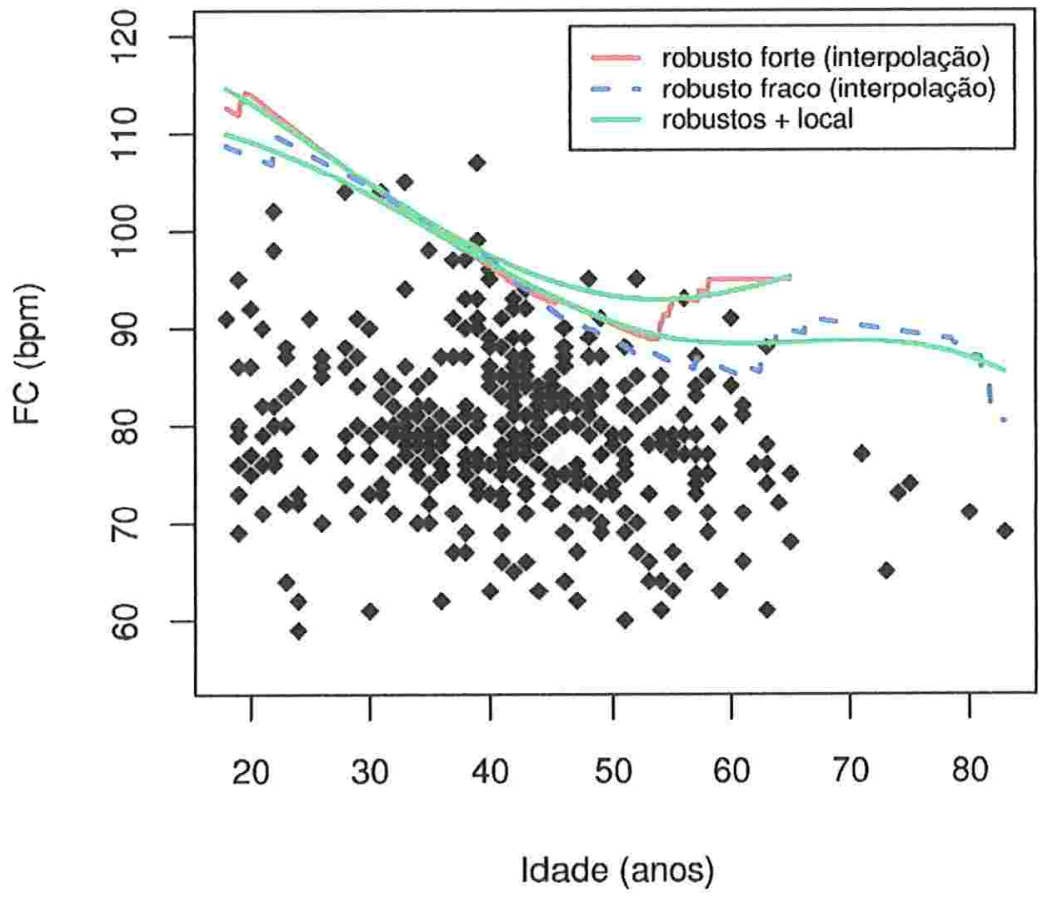

Figura 5.5: Ajustes polinomiais locais e Curvas de referência de ordem 97,5\% ajustadas considerando os métodos de "robustificação" forte e fraca.

Os ajustes polinomiais apresentados na Figura 5.5 apresentam níveis de suavização mais adequados, proporcionando desta maneira, uma interpretação prática mais apropriada. 


\section{Capítulo 6}

\section{Considerações finais}

Neste trabalho apresentamos o método de ajuste polinomial local com o objetivo de utilizá-lo na construçāo de curvas de referência. O método de regressão quantílica local foi então considerado. Modificações foram introduzidas tornando este método robusto a valores discrepantes na variável preditora $X$. Essas modificações foram motivadas por um problema na área de Cardiologia, analisado anteriormente por técnicas não robustas, que mostraram não ser apropriadas na construção de curvas de referência para indivíduos idosos, isto é, com idade acima de 65 anos.

O maior problema encontrado neste trabalho foi o cálculo do parâmetro de suavização $h$ utilizado no ajuste das curvas, uma vez que envolvem expressões complexas no aspecto computacional.

Como continuidade do trabalho, pode ser sugerido o estudo das rotinas de seleção do parâmetro de suavização $h$. Pode também ser estudada a influência de valores discrepantes na variável preditora $X$ na obtenção de $h$, nos métodos de regressão quantílica local e robusto, de forma análoga ao que foi feito em Einbeck et al. (2004).

Pode-se também sugerir um estudo das propriedades assintóticas dos procedimentos robustos apresentados neste trabalho. 


\section{Apêndice A}

\section{Variância e Viés assintóticos}

O teorema a seguir apresenta as expressões aproximadas do viés e da variância do estimador $\hat{m}^{(j)}\left(x_{0}\right)=j ! \hat{\beta}_{j}$, para $j=0, \ldots, p$. Esses resultados foram obtidos por Ruppert e Wand (1994).

Teorema. Assumindo que $f\left(x_{0}\right)>0$ e $f(),. m^{(p+1)}($.$) e \sigma^{2}($.$) são contínuas na vizinhança$ de $x_{0}$, então a variância assintótica condicional de $\hat{m}^{(j)}\left(x_{0}\right)$, quando $h \rightarrow 0$ e nh $\rightarrow \infty$ é dada por:

$$
\operatorname{Var}\left\{\hat{m}^{(j)}\left(x_{0}\right) \mid \mathbb{X}\right\}=e_{j+1}^{T} S^{-1} S^{*} S^{-1} e_{j+1} \frac{j !^{2} \sigma^{2}\left(x_{0}\right)}{f\left(x_{0}\right) n h^{1+2 j}}+o_{p}\left(\frac{1}{n h^{1+2 j}}\right)
$$

onde:

$$
\begin{aligned}
e_{j+1}^{T} & =(0, \ldots, 0,1,0, \ldots, 0) \text { é o vetor com } 1 \text { na }(j+1) \text {-ésima posição e } 0 \text { nas demais, } \\
S & =\left(\mu_{i+l}\right)_{0 \leq i, l \leq p}, \\
\mu_{i} & =\int u^{i} K(u) \mathrm{d} u, \\
S^{*} & =\left(j_{i+l}\right)_{0 \leq i, l \leq p}, \\
j_{i} & =\int u^{j} K^{2}(u) \mathrm{d} u
\end{aligned}
$$


O viés assintótico condicional, assumindo que $f^{\prime}($.$) e m^{(p+2)}($.$) são contínuas na$ vizinhança de $x_{0}$ e $n h^{3} \rightarrow \infty$, é dado por:

Viés $\left\{\hat{m}^{(j)}\left(x_{0}\right) \mid \mathbb{X}\right\}=\left\{\begin{array}{l}e_{j+1}^{T} S^{-1} c_{p} \frac{j !}{(p+1) !} m^{(p+1)}\left(x_{0}\right) h^{p+1-j}+o_{p}\left(h^{p+1-j}\right), \text { se }(p-j) \text { é ímpar, } \\ e_{j+1}^{T} S^{-1} \tilde{c}_{p} \frac{j !}{(p+2) !}\left\{m^{(p+2)}\left(x_{0}\right)+(p+2) m^{(p+1)}\left(x_{0}\right) \frac{f^{\prime}\left(x_{0}\right)}{f\left(x_{0}\right)}\right\} h^{p+2-j}+ \\ +o_{p}\left(h^{p+2-j}\right), \text { se }(p-j) \text { é par, }\end{array}\right.$

onde $e_{j+1}^{T}, S$ e $S^{*}$ são definidos como em $(\mathrm{A} .1), c_{p}=\left(\mu_{p+1}, \ldots, \mu_{2 p+1}\right)^{T}$ e $\tilde{c}_{p}=\left(\mu_{p+2}, \ldots, \mu_{2 p+2}\right)^{T}$.

As expressões (A.1) e (A.2), para $(p-j)$ ímpar, podem também ser escritas em termos do Kernel equivalente $K_{j}^{*}($.$) , na forma:$

$$
\begin{aligned}
\operatorname{Var}\left\{\hat{m}^{(j)}\left(x_{0}\right) \mid \mathbb{X}\right\} & =\int K_{j}^{* 2}(u) \mathrm{d} u \frac{j !^{2} \sigma^{2}\left(x_{0}\right)}{f\left(x_{0}\right) n h^{1+2 j}}+o_{p}\left(\frac{1}{n h^{1+2 j}}\right) \\
\operatorname{Viés}\left\{\hat{m}^{(j)}\left(x_{0}\right) \mid \mathbb{X}\right\}= & \left\{\int u^{p+1} K_{j}^{*}(u) \mathrm{d} u\right\} \frac{j !}{(p+1) !} m^{(p+1)}\left(x_{0}\right) h^{p+1-j}+ \\
& +o_{p}\left(h^{p+1-j}\right) .
\end{aligned}
$$




\section{Apêndice B}

\section{Rotina para o cálculo do parâmetro de} suavização $h$ constante

Listagem dos comandos utilizados no Software R para análise dos dados apresentados no Capítulo 1

$\underline{\text { Inicialização }}$

require(base)

require(MASS)

require(KernSmooth)

$\underline{\text { Preparação do banco de dados denominado motor obtido no Software } \mathrm{R}}$

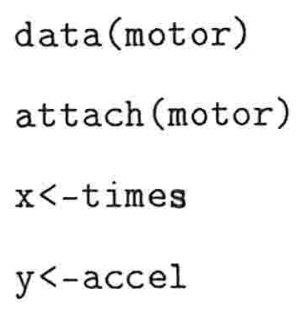


Obtenção do valor aproximado do $h$

\#fatorial é a função que calcula o fatorial de um número inteiro $x$ fatorial<-function $(x)\{$

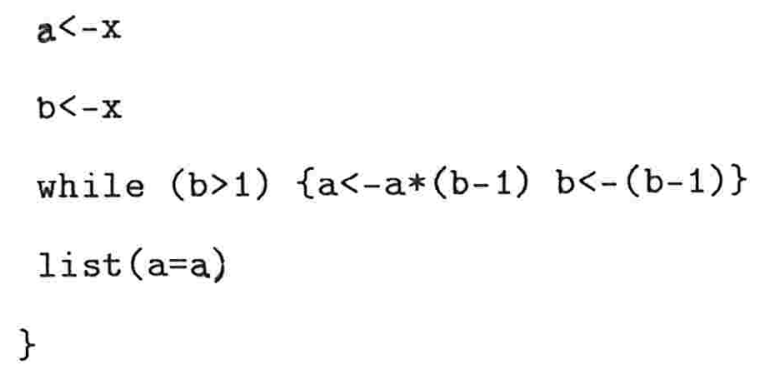

p<-1 \#p é o grau dos polinômios ajustados localmente, por exemplo, polinômios de primeiro grau $(p=1)$

const<-1.719 \#const é a constante utilizada no cálculo do h no ajuste da função de regressão, utilizando polinômios de primeiro grau e função Kernel Epanechnikov (ver Tabela 2.1)

$l i<-\min (x)$ \#menor valor de $x$ ls<-max(x) \#maior valor de $x$

fit<-lm(y poly $(x,(p+3)))$ \#ajuste do polinômio de grau $(p+3)$ sigma2<-deviance(fit)/fit\$df.residual \#estimativa do sigma2 $z<-$ fatorial $(p+1)$ 


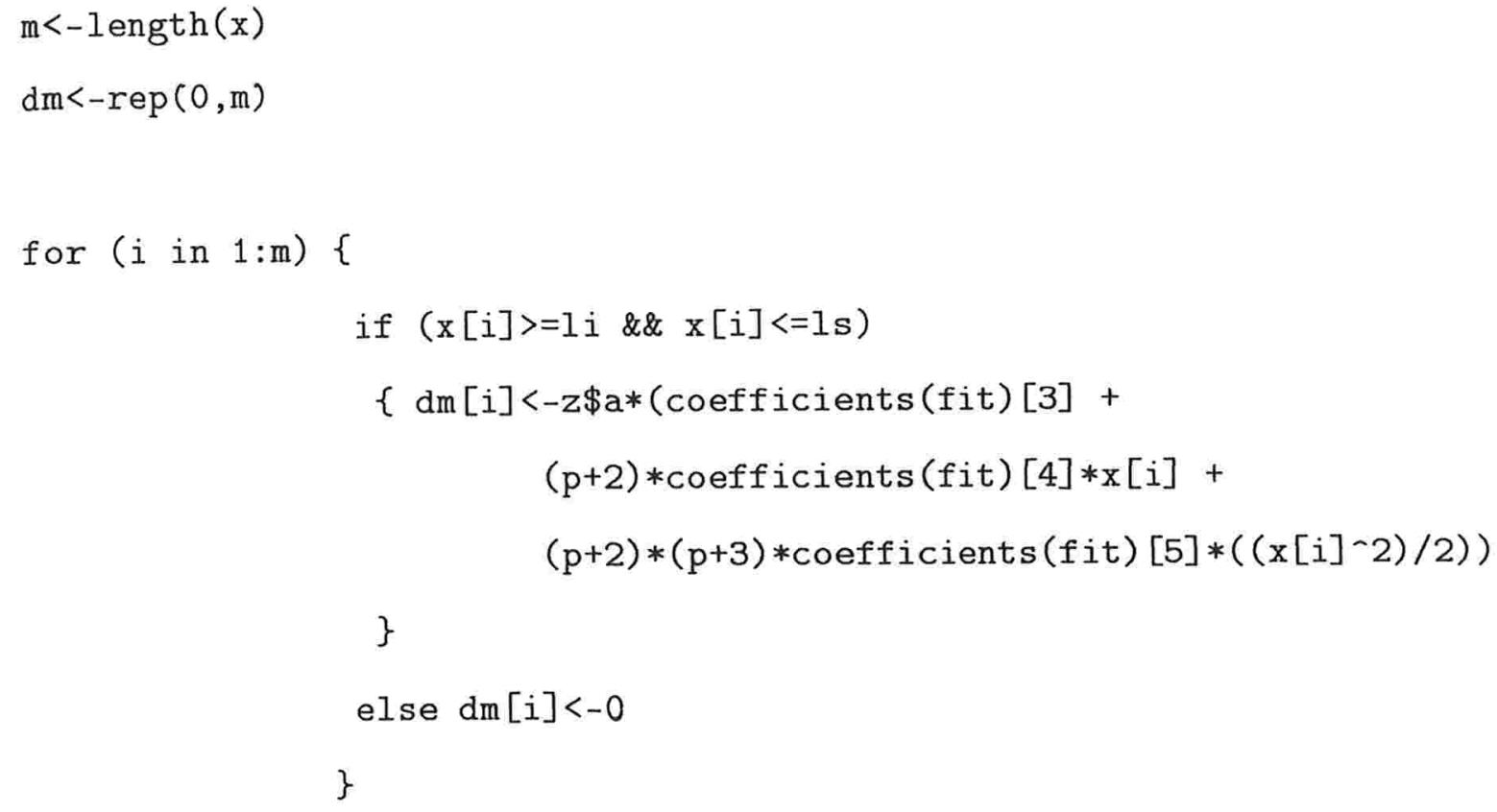

$\operatorname{somadm} 2<-\operatorname{sum}\left(\mathrm{dm}^{\wedge} 2\right)$

\# h é o valor aproximado do parâmetro de suavização ótimo $\mathrm{h}<-($ const $) *(((\operatorname{sigma} 2 *(1 \mathrm{~s}-1 \mathrm{i})) /(\operatorname{somadm} 2))-(1 /(2 * \mathrm{p}+3)))$ 


\section{Apêndice C}

\section{Rotina para o ajuste da função}

\section{quantílica}

\section{C.1 Rotina para o ajuste local da função quantílica}

Esta rotina está disponível no Software R e é utilizada para o ajuste da função quantílica local. O usuário deve fornecer o vetor $\mathrm{x}$ (valores da variável $X$ ), o vetor $\mathrm{y}$ (valores da variável $Y$ ), o parâmetro de suavização $(h)$, a ordem da função quantílica desejada (tau) e o número de pontos $(\mathrm{m})$ em que se deseja ajustar a função quantílica.

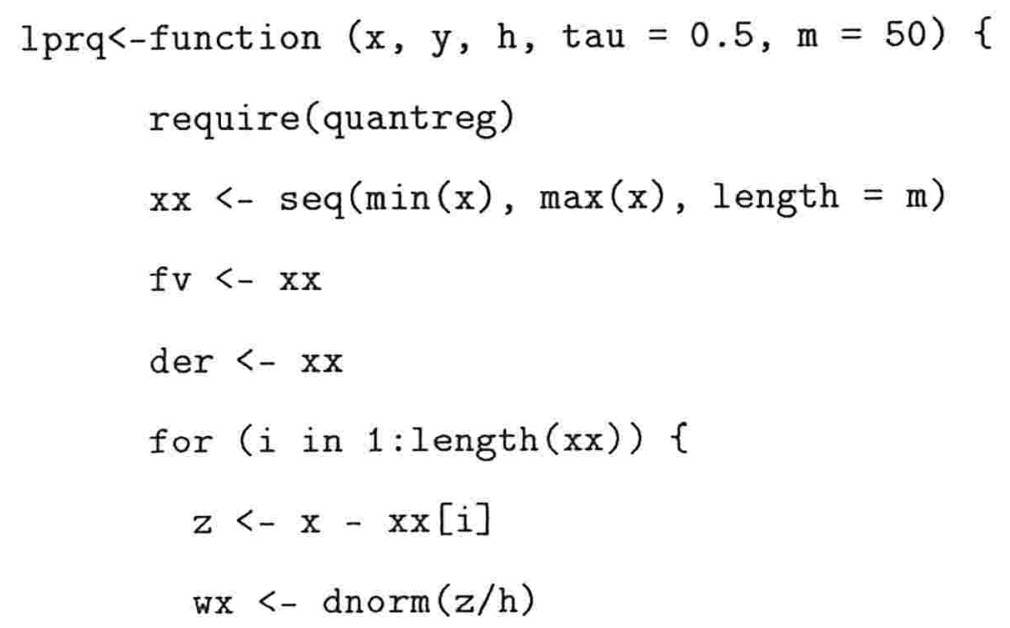




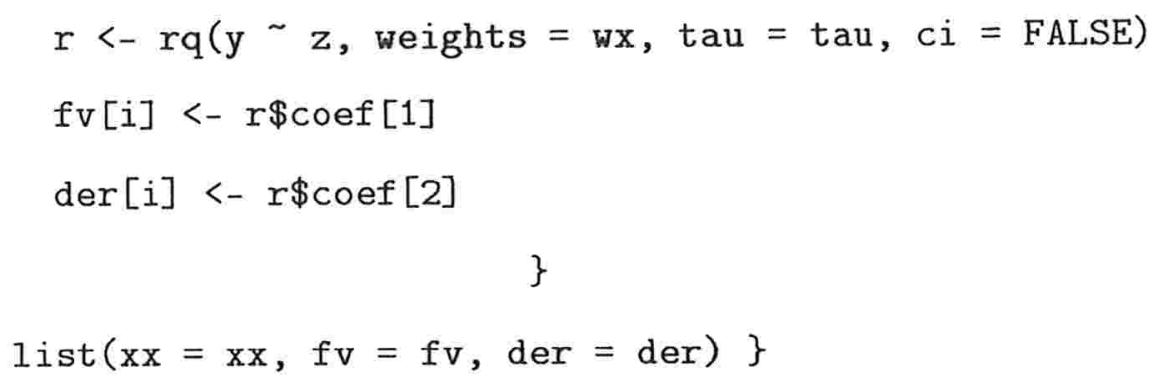

\section{C.2 Rotina para o ajuste local robusto da função quan- tílica}

Esta rotina foi feita com o objetivo de criar uma estimativa da função quantílica robusta a valores discrepantes de $X$. Como no ajuste da função quantílica local, o usuário também deve fornecer o vetor $\mathrm{x}$ (valores da variável $X$ ), o vetor $\mathbf{y}$ (valores da variável $Y$ ), o parâmetro de suavização $(h)$, a ordem da função quantílica desejada (tau) e o número de pontos $(m)$ em que se deseja ajustar a função quantílica.

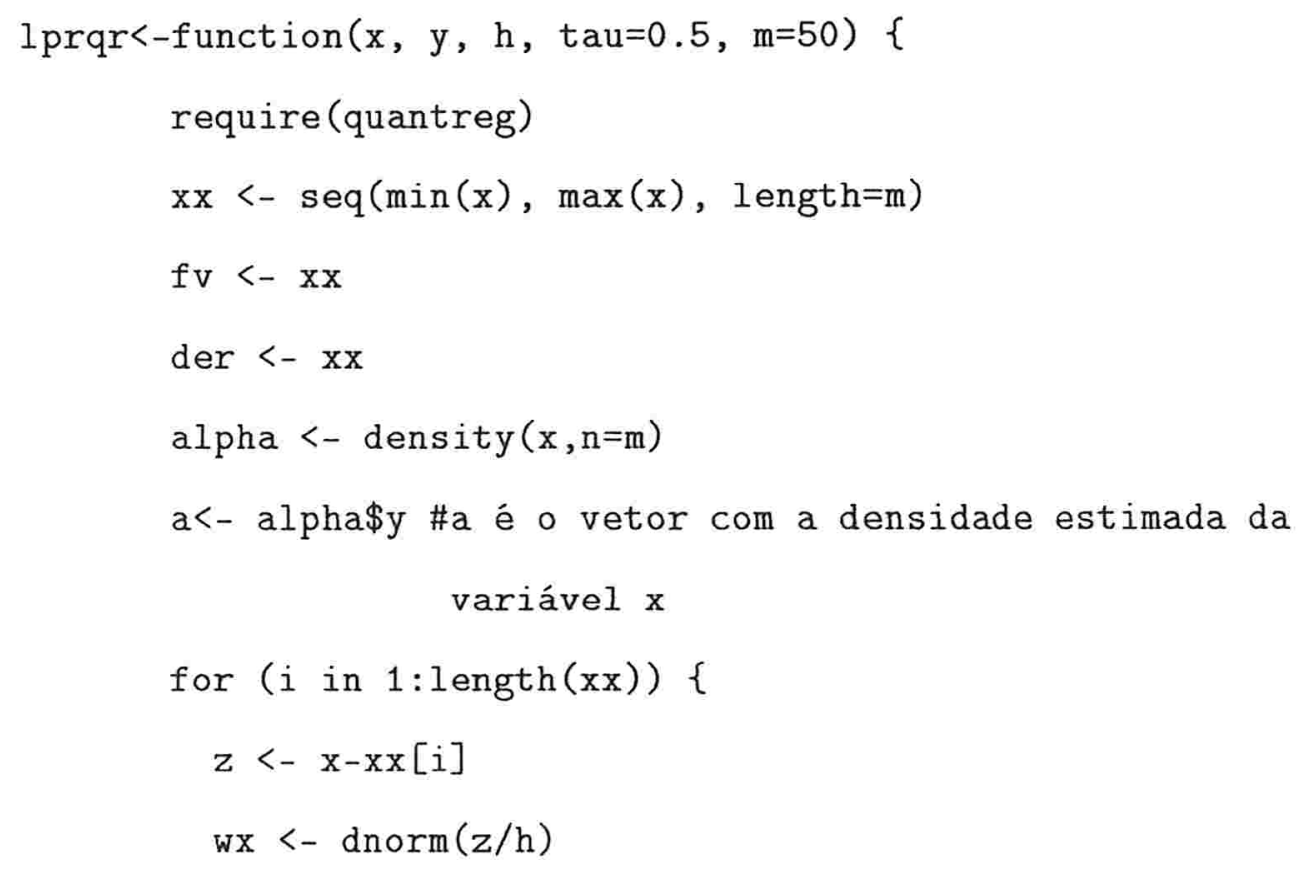




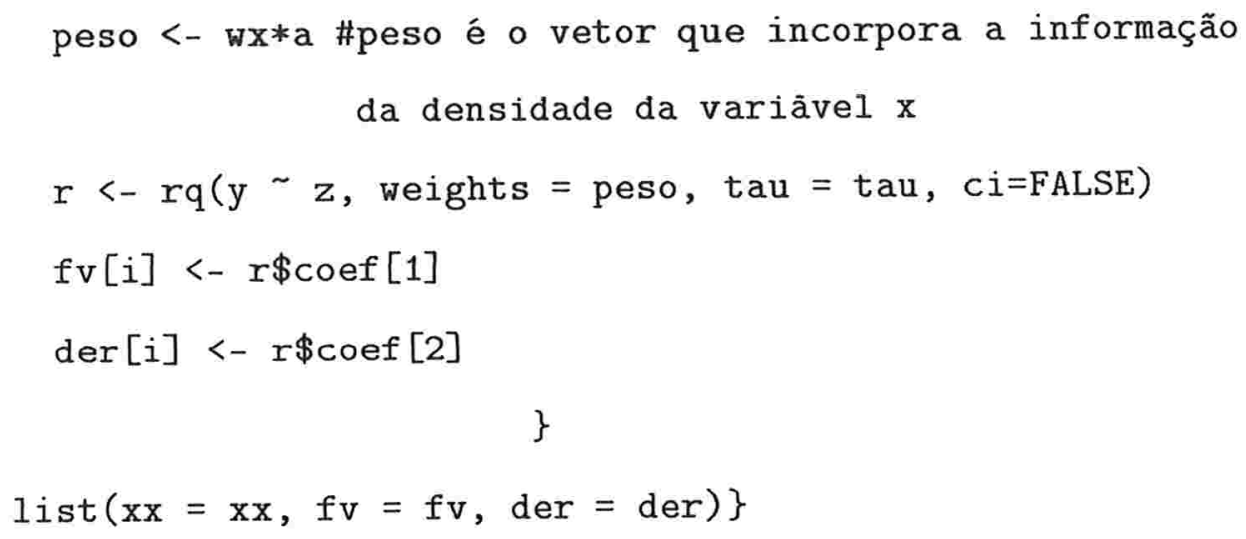




\section{Referências Bibliográficas}

Allen, A. W., Cade, B. S. e Vandever, M. W. (2001). Effects of emergency having on vegetative characteristics within selected conservation reserve program fields in the northern great plains, J. Soil and Water Conservation 56: 120-125.

André, C. D. S., Artes, R. e Vincenzi, M. A. (2002). Atividade elétrica cardíaca em indivíduos sem cardiopatia, Relatório Técnico RAE-CEA-02P12, IME - USP, São Paulo.

Buchinsky, M. (1998). Recent advances in quantile regression models: A pratical guide for empirical research, J. Human Resources 33: 88-126.

Cade, B. S., Terrell, J. W. e Schroeder, R. L. (1999). Estimating effects of limiting factors with regression quantiles, Ecology 80: 311-323.

Carroll, R. J. e Ruppert, D. (1988). Transformation and Weighting in Regression, Chapman \& Hall, New York.

Cleveland, W. S. (1979). Robust locally weighted regression and smoothing scatterplots, J. Amer. Statist. Assoc. 74: 829 836.

Cole, T. J., Freeman, J. V. e A., P. M. (1998). British 1990 growth reference centiles for weight, height, body mass index and head circumference fitted by maximum penalized likelihood, Statistics in Medicine 17: 407-429. 
de Boor, C. (1978). A Pratical Guide to Spline, Springer-Verlage, New York.

de Forest, E. L. (1873). On some methods of interpolation applicable to the graduation of irregular series, such as tables of mortality, Annual report of the board of regents, Smithsonian Institution.

Einbeck, J., André, C. D. S. e Singer, J. M. (2004). Local smoothing with robustness against outlying predictors, Environmetrics 15: 541-554.

Fahrmeir, L. e Tutz, G. (1996). Multivariate Statistical Modelling Based on Generalized Linear Models, Springer-Verlag.

Fan, J. (1992). Design-adaptive nonparametric regression, J. Amer. Statist. Assoc. 87: 9981004.

Fan, J., Gasser, T., Gijbels, I., Brockmann, M. e Engel, J. (1995). On nonparametric estimation via local polynomial regression, Discussion Paper \#9511. Institute of Statistics, Catholic University of Louvain, Louvain-la-Neuve, Belgium.

Fan, J. e Gijbels, I. (1992). Variable bandwidth and local linear regression smoothers, Ann. Statist. 20: 2008-2036.

Fan, J. e Gijbels, I. (1995). Adaptive order polynomial fitting: Bandwidth robustification and bias reduction, J. Comp. Graph. Statist. 4(3): 213-227.

Fan, J. e Gijbels, I. (1996). Local Polynomial Modelling and Its Applications, Monographs on Statistics and Applied probability, Chapman \& Hall, London.

Fitzenberg, B., Koenker, R. e Machado, J. A. F. (2002). Economic Applications of Quantile Regression, Springer, Berlin.

Gasser, T., Kneip, A. e Köhler, W. (1991). A flexible and fast method for automatic smoothing, J. Amer. Statist. Assoc. 86(415): 643-652.

62. 
Green, P. J. e Silverman, B. W. (1994). Nonparametric Regression and Generalized Linear Models: a Roughness Penalty Approach, Chapman \& Hall, London.

Harris, E. K. e Boyd, J. C. (1995). Statistical Bases of Reference Values in Laboratory Medicine, Marcel Dekker, New York.

Hastie, T. J. e Tibshirani, R. J. (1990). Generalized Additive Models., Chapman \& Hall, London.

Heagerty, P. J. e Pepe, M. S. (1999). Semiparametric estimation of regression quantiles with application to standardizing weight for height and age in us children, Applied Statistics 48: 533-551.

Härdle, W. (1990). Smoothing Techniques with Implementation in S, Springer-Verlag, New York.

Kimeldorf, G. S. e Wahba, G. (1970). A correspondence between bayesian estimation on stochastic processes and smoothing by splines, Ann. Math. Statist. 41: 495-502.

Koenker, R. e Bassett, G. (1978). Regression quantiles, Econometrica 46: 33-50.

Koenker, R. e Hallock, K. F. (2001). Quantile regression: An introduction, Journal of Economic Perspectives 15(4): 143-156.

Martins, P. S. e Pereira, P. T. (2004). Does education reduce wage inequality? quantile regresion evidence from 16 countries, Labour Economics 11: 355-371.

Marx, B. D. e Eilers, P. H. (1998). Direct generalized additive modelling with penalized likelihood, Computacional Statistics and Data Analysis 28: 193-209.

Müller, H.-G. (1988). Nonparametric Regression Analysis of Longitudinal Data., Vol. 46 of Lecture Notes in Statistics, Springer-Verlag, Berlin. 
Nadaraya, E. A. (1989). Nonparametric Estimation of Probability Densities and Regression Curves, Kluwer Academic Publishers, Boston. Translate by S. Kotz.

Neter, J., Kutner, M. H., Nachtsheim, C. J. e Wasserman, W. (1996). Applied Linear Statistical Models, Irwin, London.

Reinsch, C. (1967). Smoothing by spline functions, Numer. Math. 10: 177-183.

Royston, P. (1991). Constructing time-specific reference ranges, Statistics in Medicine 10: $675-690$.

Royston, P. e Wright, E. M. (1998). A method for estimating age-specific reference intervals ('normal ranges') based on fraction polynomials and exponetial transformation, Journal of Royal Statistical Society, Series A 161: 79-101.

Ruppert, D., Sheather, S. J. e Wand, M. P. (1995). An effective bandwidth selector for local least squares regression, J. Amer. Statist. Assoc. 90: 1257-1270.

Ruppert, D. e Wand, M. P. (1994). Multivariate weighted least squares regression, Ann. Statist. 22: 1346-1370.

Sañudo, A. (2000). Intervalos de confiança para curvas percentuais de peso fetal estimado em gestações gemelares, Dissertação de mestrado, Instituto de Matemática e Estatística - USP.

Scharf, F. S., Juanes, F. e Sutherland, M. (1998). Inferring ecological relationships from the edges of scatter diagrams: comparison of regression techniques, Ecology 79: 448-460.

Schiaparelli, G. V. (1866). Sul modo di ricavare la vera espressione delle leggi delta natura dalla curve empiricae, Effemeridi Astronimiche di Milano per l'Arno 857: 3-56.

Schimidt, G., Mattern, R. e Schüler, F. (1981). Biomechanical investigation to determine physical and traumatological differentiation criteria for the maximum load capacity 
of head and vertebral column with and without protective helmet under effects of impact, Final Report Phase III 65, Institut für Rechtsmedizin, Universität Heidelberg, Germany.

Schoenberg, I. J. (1964). Spline functions and the problem of graduation, Proc. Nat. Acad. Sci. 52: 947-950. USA.

Silverman, B. W. (1986). Density Estimation for statistics and Data Analysis, Chapman \& Hall, London.

Sultan, A. (1993). Linear Programming, Academic Press, San Diego.

Tavares, R. A. (1998). Seleção de variáveis em regressão $l_{1}$, Dissertação de mestrado, Instituto de Matemática e Estatística - USP.

Yu, K. e Jones, M. C. (1998). Local linear quantile regression, J. Amer. Statist. Assoc. 93(441): 228-237. 